Fotoprotetores Orgânicos: Pesquisa, Inovação e a Importância da Síntese Orgânica

\author{
Nascimento, L. F.; Santos, E. P.; Aguiar, A. P.*
}

Rev. Virtual Quim., 2014, 6 (2), 190-223. Data de publicação na Web: 8 de dezembro de 2013

http://www.uff.br/rvq

\title{
Organic Sunscreens. Research, Innovation and the Organic Synthesis Importance
}

\begin{abstract}
Sunscreens are used to prevent skin damage due to sunlight ultraviolet radiation (UVR). These compounds can be obtained from natural solar filters, from nanocompounds and, mainly, from synthetic organic compounds. The production of ideal organic sunscreens is related to a better understanding of safety and efficacy of these compounds. The ideal organic sunscreens must protect the skin against UVB-rays (290-320 nm) and UVA-rays (320-400 nm), also presenting a safe sun protection factor (SPF), have good photostability and do not present phototoxicity. This review reports the main general aspects, synthesis and scientific studies of organic and commercial sunscreens.
\end{abstract}

Keywords: Organic synthesis; organic sunscreens; ultraviolet radiation.

\section{Resumo}

Protetores solares são usados para evitar danos a pele devido a radiação ultravioleta (UV) da luz solar. Estes produtos podem ser obtidos a partir de filtros solares naturais, nanocompostos e principalmente compostos orgânicos sintéticos. A produção de novos compostos ideais esta associada a um melhor entendimento sobre a segurança e eficácia dos protetores solares orgânicos. Um fotoprotetor orgânico ideal deve proteger a pele contra os raios UVB (290-320 nm) e UVA (320-400 nm), possuir um fator de proteção solar (FPS) seguro, ser fotoestável e não ser fototóxico. Esta revisão reporta os principais aspectos gerais, síntese e estudos científicos de fotoprotetores orgânicos e comerciais.

Palavras-chave: Síntese orgânica; fotoprotetores orgânicos; radiação ultravioleta.

\footnotetext{
* Instituto Militar de Engenharia, Seção de Engenharia Química, Divisão de Ensino e Pesquisa, Praça General Tibúrcio, 80, CEP 22290-270, Rio de Janeiro-RJ, Brasil.

Malcino@ime.eb.br

DOI: $10.5935 / 1984-6835.20140015$
} 


\title{
Fotoprotetores Orgânicos: Pesquisa, Inovação e a Importância da Síntese Orgânica
}

\author{
Luciano F. do Nascimento, ${ }^{a, c}$ Elisabete P. dos Santos, ${ }^{b}$ Alcino P. de \\ Aguiar $^{\mathrm{a}, *}$
}

a Instituto Militar de Engenharia, Seção de Engenharia Química, Divisão de Ensino e Pesquisa, Praça General Tibúrcio, 80, CEP 22290-270, Rio de Janeiro-RJ, Brasil.

${ }^{\text {b }}$ Universidade Federal do Rio de Janeiro, Centro de Ciências da Saúde, Faculdade de Farmácia, Laboratório de Desenvolvimentos Galênicos, Bloco K, Sala 50, 2ํandar, CEP 21941-590, Ilha do Fundão, Rio de Janeiro-RJ, Brasil.

' Universidade Unigranrio, Escola de Ciência e Tecnologia, Curso de Graduação em Química, Rua Prof. José de Souza Herdy, 1.160, 25 de Agosto, CEP 25071-202, Duque de Caxias-RJ, Brasil.

*alcino@ime.eb.br

Recebido em 24 de outubro de 2012. Aceito para publicação em 8 de outubro de 2013

\section{Introdução}

1.1. Aspectos Históricos

1.2. Radiação Solar

1.3. Câncer de Pele

1.4. Agentes Fotoprotetores

1.5. Fator de Proteção Solar

\section{Fotoprotetores Orgânicos}

2.1. Fotoprotetores Orgânicos Comerciais

2.2. Pesquisa e Inovação em Fotoprotetores Orgânicos

2.3. Protocolo de Fotoproteção

\section{Considerações Finais}

\section{Introdução}

Segundo a ABIHPEC, Associação Brasileira da Indústria de Higiene Pessoal, Perfumaria e Cosméticos, o segmento cosmético nacional apresentou um crescimento médio deflacionado de $10 \%$ nos últimos 16 anos, passando de um faturamento líquido de imposto sobre venda de $\mathrm{R} \$ 4,9$ bilhões em 1996 para R\$2 29,4 bilhões em 2011. O Brasil ocupa atualmente a 2 a posição mundial em comercialização de protetores solares e a 3ạ posição no setor cosmético em geral. Dentre os fatores que são apontados como responsáveis pelo excelente crescimento neste setor, podem ser destacados a 
utilização de tecnologia de ponta e o lançamento constante de novos produtos. ${ }^{1}$

Muito recentemente, em 2012, a ANVISA, Agência Nacional de Vigilância Sanitária, atualizou a classificação do protetor solar como sendo "qualquer preparação cosmética destinada a entrar em contato com a pele $e$ lábios, com a finalidade exclusiva ou principal de protegê-la contra a radiação UVB e UVA, absorvendo, dispersando ou refletindo a radiação". 2

Tendo em vista o avanço deste segmento, a constante inovação através da pesquisa e do desenvolvimento e a amplitude do tema, há necessidade da divulgação contínua de artigos de revisão sobre os diversos aspectos que norteiam o tema protetores solares. ${ }^{3-9}$

\subsection{Aspectos históricos}

A cultura de exposição ao sol e a pele bronzeada como sinônimo de saúde teve seu início no começo do século XX. Em função disso, os primeiros produtos cosméticos deste segmento foram os óleos bronzeadores que potencializavam a ação dos raios solares. Em 1928, nos Estados Unidos, foi comercializado o primeiro protetor solar e este consistia numa emulsão empregando salicilato de benzila e cinamato de benzila como agentes fotoprotetores. Através da constatação de que tais produtos prolongavam a exposição ao sol e preveniam queimaduras na pele, os protetores solares foram difundidos, uma vez que em 1930 ocorreram os primeiros relatos correlacionando problemas de pele à exposição solar. ${ }^{10} \mathrm{O}$ ácido $p$-aminobenzoico e seus derivados, inseridos em bases para pomadas, foram utilizados como princípios ativos em protetores solares a partir de 1943. As primeiras recomendações pela agência americana Food and Drug Administration (FDA) para o uso de produtos para proteção solar ocorreram em 1972 e o conceito de fotoprotetores foi reconhecido e adotado a partir de 1978 , onde os filtros solares foram reclassificados de cosméticos para medicamentos de fins preventivos. ${ }^{11} \mathrm{Em} 1999$ o FDA publicou uma lista contendo 14 filtros solares considerados seguros e eficazes para uso sem prescrição médica. Iniciada em 2007, uma nova regulamentação vem sendo elaborada pela FDA com uma proposta mais abrangente que vai desde as formulações até os ensaios de fotoproteção nos produtos finais. ${ }^{12}$ Atualmente, as agências reguladoras mundiais publicaram diversas normativas no intuito de uma melhor padronização, segurança e eficácias dos produtos fotoprotetores comercializados. ${ }^{2,13,14}$

\subsection{Radiação solar}

Os raios do sol que atingem a superfície terrestre são essenciais para que haja vida em nosso planeta e apesar de toda extensão do espectro eletromagnético, estes raios são compostos por uma pequena faixa predominante (Tabela 1). ${ }^{4-6,10,11,15-17}$

Tabela 1. Radiações que compõe os raios do sol ${ }^{4-6,10,11,15-17}$

\begin{tabular}{cccc}
\hline Radiação & $\begin{array}{c}\text { Comprimento } \\
\text { de ondas (nm) }\end{array}$ & $\begin{array}{c}\text { Energia } \\
\text { (KJ/mol) }\end{array}$ & $\begin{array}{c}\text { Incidência } \\
\text { terrestre (\%) }\end{array}$ \\
\hline Infravermelho (IV) & $800-5.000$ & $0,12-150$ & $40-50$ \\
Visível (VIS) & $400-800$ & $150-310$ & $40-50$ \\
Ultravioleta (UV) & $100-400$ & $310-12.000$ & $05-10$ \\
\hline
\end{tabular}

O corpo humano detecta estas radiações de diferentes formas. Os efeitos da radiação
IV são percebidos pelo calor durante o aumento da temperatura, a região do VIS é 
detectada pelas diferentes cores através do sistema ótico e os raios UV, mais energéticos, promovem reações fotoquímicas na pele humana. A radiação UV é menos incidente na superfície terrestre, pois é absorvida pelo oxigênio e pela camada de ozônio na estratosfera. Contudo, as ondas eletromagnéticas de menores comprimentos de onda ( $\lambda$ ) são as mais energéticas, portanto, a radiação UV é a que possui maior impacto sobre a saúde humana. Todavia, a radiação UV ainda possui subdivisões em função de diferentes comprimentos de ondas (Tabela 2). 2,6,11,12,15,18

Tabela 2. Divisões da radiação UV 2,6,11,12,15,18

\begin{tabular}{ccc}
\hline Radiação UV & Comprimento de ondas $\left(\boldsymbol{\lambda}_{\mathrm{nm}}\right)$ & Incidência terrestre (\%) \\
UVA I & $340-400$ & 95 \\
UVA II & $320-340$ & \\
UVB & $290-320$ & 05 \\
UVC & $200-290$ & - \\
UV-vácuo & $100-200$ & - \\
\hline
\end{tabular}

A intensidade da radiação UV na superfície terrestre possui diversos fatores de variação, tais como a poluição atmosférica, a existência de nuvens, a umidade relativa do ar, o horário do dia, a estação do ano, a altitude e a latitude. Outros fatores podem influenciar, indiretamente, através da reflexão ou dispersão dos raios UV, são eles, a água, o acrílico, o vidro, a areia da praia, a neve e até mesmo $o$ asfalto. ${ }^{4,10,15}$

Os raios UVC não chegam a Terra, pois são bloqueados pela camada de ozônio. Atualmente, sabe-se que tanto os raios UVB, mais energéticos, quanto os raios UVA, menos energéticos, são responsáveis por diversos problemas de pele, sendo o tempo para o diagnóstico o fator diferencial entre ambos. ${ }^{19,20}$ Entretanto, os raios UVA penetram mais profundamente na pele, chegando à derme, e promovendo sua pigmentação através da produção de melanina pelos melanócitos, mas também são responsáveis pelo fotoenvelhecimento cutâneo e pela fotossensibilidade ocular, dentre outros danos à saúde. ${ }^{21} \mathrm{~A}$ radiação UVB penetra somente até a epiderme e é responsável pela produção natural da vitamina $D_{3}$, importante para a absorção de cálcio na estrutura óssea. Contudo, uma exposição demasiada aos raios UVB podem acasionar sérios problemas cutâneos que vão desde queimaduras até o câncer de pele. ${ }^{10,12,25,22,23}$

\subsection{Câncer de pele}

Dentre os diversos problemas de saúde ocasionados por uma exposição excessiva aos raios solares, tais como sensibilidade à luz, manchas na pele, despigmentação cutânea, queimadura solar, envelhecimento da pele e supressão do sistema imunológico, o câncer de pele é o de maior gravidade. ${ }^{21,23-25} 0$ tipo de pele de cada indivíduo possui uma correlação direta com os fatores externos relacionados à incidência de radiação UV e com o câncer de pele. ${ }^{22,25} \mathrm{~A}$ escala Fitzpatrick classifica os diversos tipos de pele e suas respectivas sensibilidades à radiação UV. Por exemplo, o Tipo I é para a pele muito clara, que sempre se queima e nunca se bronzeia, enquanto o Tipo $\mathrm{VI}$, corresponde à pele negra, que nunca se queima e sempre se bronzeia. ${ }^{5,26}$

A ocorrência de eritemas e até mesmo o câncer de pele está associada à formação das espécies reativas de oxigênio (EROs), como o 
oxigênio singleto $\left({ }^{1} \mathrm{O}_{2}\right)$, o peróxido de hidrogênio $\left(\mathrm{H}_{2} \mathrm{O}_{2}\right)$, o radical ânion superóxido $\left(\mathrm{O}_{2}{ }^{-}{ }^{-}\right)$e o radical hidroxila $\left(\mathrm{HO}{ }^{\circ}\right){ }^{19,23,27,28}$ Estas espécies são formadas pela ação dos raios UV e implicam na ruptura da cadeia do DNA. A reconexão da cadeia com a ordem de suas bases trocadas é o processo básico da mutação genética. ${ }^{19,27}$ Especificamente, elas atuam na ativação da cascata intracelular de sinalização do processo de transcrição, expressão dos genes, e na ativação de vários receptores de membrana para mediadores pró-inflamatórios. ${ }^{18,23}$ A carcinogênese cutânea também está associada ao alto nível de produção de dímeros de pirimidina. Quando o DNA absorve as radiações UV, principalmente UVB, este processo pode favorecer os processos mutagênicos. ${ }^{5,12,24}$ Assim, a ação dos raios UVB no DNA provoca uma divisão celular acelerada produzindo novas células tumorigênicas. ${ }^{24,26}$

O câncer de pele pode ser do tipo não melanoma ou melanoma (Figura 1). ${ }^{29} \mathrm{O}$ não melanoma (A) ainda pode ser classificado de acordo com camada da pele onde ele se desenvolve, sendo o carcinoma basocelular e - carcinoma espinocelular os tipos mais comuns. Este tipo de câncer de pele é o de maior ocorrência, porém, o de menor mortalidade. Quando diagnosticado a tempo, o não melanoma possui um índice de cura de $95 \%{ }^{26}$ Apesar de ser o de menor frequência, o câncer de pele do tipo melanoma (B) é o que apresenta maiores casos de morte, principalmente pela ocorrência de metástase. O melanoma cutâneo ocorre nos melanócitos, células onde há produção de melanina, que é uma substância de proteção natural da pele contra os raios UV. ${ }^{30}$

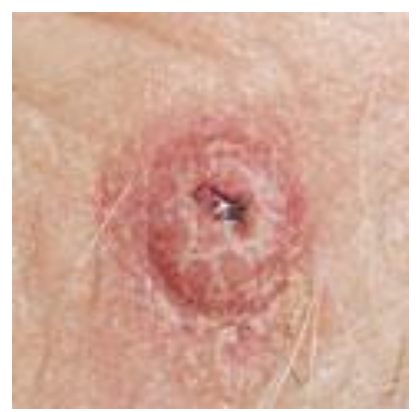

A

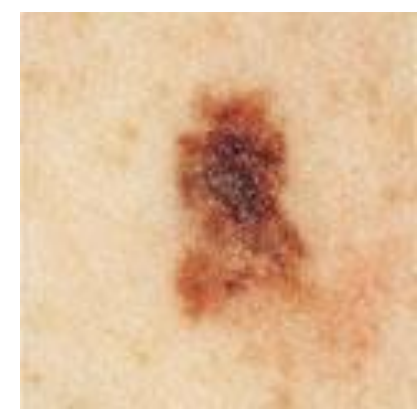

B

Figura 1. Fotos de câncer de pele não melanoma (carcinoma epidérmico de células escamosas - A) e melanoma (tumor maligno - B). Reprodução autorizada da ref. 29, Copyright(C World Health Organization (WHO), 2012

A Organização Mundial da Saúde estima que ocorram entre 2 e 3 milhões de novos casos de câncer de pele no mundo a cada ano. Destes, 130.000 são do tipo melanoma com um total de 66.000 mortes..$^{29}$ No Brasil, o Instituto Nacional do Câncer (INCA) aponta o câncer de pele como o tipo de câncer mais comum, correspondendo a $25 \%$ de todos os tumores. O INCA registrou 1.392 mortes acometidas por melanoma no ano de 2009 e 1.507 mortes para o não melanoma em 2010. A estimativa para o ano de 2012 em nosso país é que ocorram mais de 130.000 e 6.000 novos casos de não melanoma e melanoma, respectivamente..$^{30,31}$

Francis e colaboradores revisaram os diversos agentes químicos disponíveis para o tratamento preventivo do câncer de pele e destacaram a importância do uso dos fotoprotetores. $^{32}$ O INCA e a Sociedade Brasileira de Dermatologia (SBD) possuem campanhas contra o câncer de pele onde o foco principal é a prevenção. Dentre as medidas preventivas divulgadas, o uso frequente de filtro solar se destaca por sua eficácia. ${ }^{30,33}$ Estudos recentes apontam que a prevenção destas doenças está ligada a necessidade de proteção contra UV em largo 
espectro (UVA-UVB), ${ }^{9,19,21,34}$ principalmente para as pessoas que exercem atividades frequentemente expostas aos raios solares, como no caso de atividades esportivas. ${ }^{35}$

\subsection{Agentes fotoprotetores}

Um filtro solar consiste numa preparação cosmética que contém agentes fotoprotetores. Tais agentes minimizam os efeitos deletéricos dos raios UV através da absorção, da reflexão ou da difusão dos raios incidentes. ${ }^{10}$ Segundo Flor e colaboradores, estas substâncias são comumente classificadas como "filtros físicos" ou "filtros químicos". Contudo, esta designação não é adequada, pois o mecanismo de ação dos fotoprotetores envolve, em sua maioria, processos físicos. Assim, a classificação apropriada para estas substâncias é em orgânicas ou inorgânicas, em função da sua respectiva natureza química. ${ }^{6} \mathrm{Em}$ geral, os compostos orgânicos agem via absorção e os inorgânicos através da reflexão dos raios UV, haja vista a classificação inicialmente empregada, "absorvedores" para os orgânicos e "refletores" para os inorgânicos. ${ }^{3,5}$

As substâncias inorgânicas empregadas como fotoprotetores são o óxido de zinco e o dióxido de titânio. Estes óxidos apresentam excelente proteção contra os raios UV, além de possuírem baixo potencial de irritação. Contudo, de acordo com o tamanho das partículas sólidas do $\mathrm{ZnO}$ e do $\mathrm{TiO}_{2}$, o produto pode deixar uma película branca sobre a pele o que é esteticamente desfavorável. ${ }^{6}$ A ANVISA, através da Resolução RDC número 47, de 16 de março de 2006, restringiu o uso destes fotoprotetores inorgânicos em uma concentração máxima de $25 \%^{36}$

Os fotoprotetores orgânicos são comumente classificados em filtros UVA e UVB, de acordo com a região de proteção UV. Isto ocorre, pois estes compostos quase sempre não possuem um amplo espectro de proteção, como por exemplo, as benzofenonas e as avobenzonas que protegem somente em UVA e os salicilatos e cinamatos que agem exclusivamente contra os raios UVB. ${ }^{11} \mathrm{~A}$ Tabela 3 apresenta alguns fotoprotetores orgânicos e suas respectivas dosagens máximas permitidas, bem como suas respectivas faixas de absorção. ${ }^{12,36}$

Tabela 3. Fotoprotetores orgânicos com suas dosagens e absorções UV ${ }^{12,36}$

\begin{tabular}{|c|c|c|c|}
\hline Fotoprotetores orgânicos & $\begin{array}{c}\text { Faixa de } \\
\text { absorção (nm) }\end{array}$ & $\begin{array}{l}\text { Proteção } \\
\text { UV }\end{array}$ & $\begin{array}{l}\text { Dosagem } \\
\text { máxima (\%) }\end{array}$ \\
\hline Ácido $p$-aminobenzoico ${ }^{a}$ & $260-313$ & UVB & 15 \\
\hline Ácido fenilbenzimidazolssulfônico ${ }^{a}$ & $290-320$ & UVB & 04 \\
\hline $\begin{array}{c}\text { 1-(4-t-butilfenil)-3-(4-metóxifenil)-1,3-propadiona }{ }^{a} \\
\left.\text { (Avobenzona }{ }^{b}\right)\end{array}$ & $310-400$ & UVA & 03 \\
\hline 4-metóxicinamato de 2-etóxietila ${ }^{a}$ (inoxato $^{b}$ ) & $270-328$ & UVB & 03 \\
\hline 2,2'-di-hidróxi-4-metóxibenzofenona ${ }^{a}$ (Dioxibenzona ${ }^{b}$ ) & $260-380$ & UVA-UVB & 03 \\
\hline $\begin{array}{l}\text { 3,3'-(1,4-fenilenodimetileno)bis[7,7-dimetil-2-oxo- } \\
\text { biciclo[2.2.1]1-heptilmetanossulfonado de sódio] }{ }^{\mathrm{a}}\left(\text { Ecamsule }{ }^{\mathrm{b}}\right)\end{array}$ & $290-400$ & UVA-UVB & 10 \\
\hline Salicilato de 3,3,5-trimetilcicloexila ${ }^{a}$ Homosalato $^{b}$ ) & $300-310$ & UVB & 15 \\
\hline 4-metóxicinamato de 2-etilexila (Metóxicinamato de octila ${ }^{\mathrm{c}}$ ) & $270-328$ & UVB & 10 \\
\hline Salicilato de 2-etilexila ${ }^{a}$ (Salicilato de octila ${ }^{c}$ ) & $300-310$ & UVB & 05 \\
\hline 2-hidróxi-4-metóxibenzofenona ${ }^{\mathrm{a}}$ (Oxibenzona ${ }^{\mathrm{b}}$ ) & $270-350$ & UVA-UVB & 06 \\
\hline 4-dimetilaminobenzoato de 2-etilexila ${ }^{a}$ (Padimato $O^{b}$ ) & $290-315$ & UVB & 08 \\
\hline $\begin{array}{l}\text { Salicilato de } 2,2^{\prime}, 2^{\prime \prime} \text {-tri-hidróxitrietilamônio }{ }^{a} \\
\left.\text { (Salicilato de trolamina }{ }^{b}\right)\end{array}$ & $260-320$ & UVB & 12 \\
\hline
\end{tabular}


Ácido 5-benzoil-4-hidróxi-2-metóxibenzenossulfônico a (Sulisobenzona ${ }^{b}$ )

$270-360$

UVA-UVB

10

Nomenclaturas: ${ }^{a}$ IUPAC (International Union of Pure and Applied Chemistry); ${ }^{b}$ USAN (United States Adopted Name); ${ }^{\mathrm{C}} \mathrm{INCl}$ (International Nomenclature for Cosmetic Ingredients).

\subsection{Fator de Proteção Solar}

A ação fotoprotetora de um filtro solar é medida universalmente através do fator de proteção solar (FPS). Este fator estabelece o aumento do tempo à exposição solar com o produto fotoprotetor aplicado sem a ocorrência de eritema, ou seja, quanto maior - FPS maior será o tempo permitido para uma exposição segura. ${ }^{12} \mathrm{O}$ FPS é aplicado exclusivamente às radiações UVB, pois estas são as causadoras de eritemas. Sob mesmas condições, uma pessoa de pele clara
(Fitzpatrick I a III) que apresenta eritema logo após 10 minutos de exposição sem o filtro solar, poderá ficar 15 vezes mais (2 horas e 30 minutos) se estiver usando um produto fotoprotetor com valor de FPS igual a $15 . .^{4,15}$ O FPS é calculado pela razão entre a energia UVB suficiente para a ocorrência da dose mínima eritematosa (DME) na pele fotoprotegida e a pele sem filtro solar (Equação 1). A DME é a dose de energia capaz de iniciar a produção de eritemas nítidos observados entre 16 e 24 horas após a exposição à radiação UVB. ${ }^{2,12,37}$

$$
F P S=\frac{D M E(\text { na pele fotoprotegida })}{D M E(\text { na pele fotodesprotegida })}
$$

Os valores de FPS comuns, comerciais, vão de 6 a 50, podendo chegar a 100 para casos específicos, ${ }^{2}$ e a forma mais precisa para a avaliação destes valores é em seres humanos. A avaliação in vivo requer um mínimo de 25 voluntários para um teste estatisticamente satisfatório e com tipos de pele de I a III, segundo a escala Fitzpatrick. A quantidade padronizada de produto aplicado deve ser de $2 \mathrm{mg} / \mathrm{cm}^{2}$ numa área mínima de $50 \mathrm{~cm}^{2}$, sob irradiação simulada $(94 \%$ de 290-400 nm). ${ }^{38}$ Assim, a eficiência de um produto está relacionada ao FPS e a sua dosagem. Contudo, o FPS não possui uma linearidade de proteção UVB e o seu valor somente será alcançado a partir da aplicação da sua porção mínima padronizada (Tabela 4). Desta forma, um FPS 15 já absorve cerca de $93 \%$ dos raios UVB, mas desde que aplicado corretamente, se não, por exemplo, numa aplicação quatro vezes menor $(0,5$ $\mathrm{mg} / \mathrm{cm}^{2}$ ) este FPS sofrerá uma redução para $2,0.9,10,12,38,39$

Tabela 4. Influência da dosagem no FPS-UVB ${ }^{10,12}$

\begin{tabular}{ccccc}
\hline FPS & $\begin{array}{c}\text { Proteção UVB } \\
\text { aproximada (\%) }\end{array}$ & \multicolumn{4}{c}{ FPS/aplicação de filtro solar $\left(\mathbf{m g} / \mathbf{c m}^{\mathbf{2}}\right)$} \\
2 & 50 & 2,0 & $\mathbf{1 , 0}$ & $\mathbf{0 , 5}$ \\
4 & 75 & 4,0 & 1,4 & 1,2 \\
8 & 87 & 8,0 & 2,0 & 1,4 \\
15 & 93 & 15,0 & 3,9 & 1,7 \\
30 & 96 & 30,0 & 5,5 & 2,0 \\
\hline
\end{tabular}


O ensaio de FPS em humanos é acurado e indispensável, porém deve ser o último estágio em uma bateria de testes de fotoproteção, pois depende da seleção de voluntários, possui alto custo, além de depender também do acompanhamento de técnicos especializados e de médicos. ${ }^{37}$ Dentre os métodos de FPS in vitro, ${ }^{37,40-43}$ o espectrofotométrico desenvolvido por Mansur e colaboradores se destaca pela boa correlação ao teste in vivo, além da agilidade e acessibilidade (Equação 2). Este método consiste na diluição do filtro a $0,2 \mu \mathrm{L} / \mathrm{mL}$ em solventes apropriados (álcool ou éter) e a posterior varredura espectrofotométrica de 290 a $320 \mathrm{~nm}^{44}$ Os valores das absorbâncias em intervalos de $5 \mathrm{~nm}$ são multiplicados pelos valores ponderais normalizados em função da ocorrência de eritemas pela faixa da absorção UVB (Tabela 5). Desta forma a ocorrência acentuada de eritema será mais favorecida na faixa onde ocorre o maior multiplicador (300 a $310 \mathrm{~nm}$; 0,2874 a $0,1864) .{ }^{44,45}$ Ao final é acrescido um fator de correção (FC $=10)$ de acordo com o FPS in vivo da FDA que emprega uma preparação contendo $8 \%$ de homosalato. ${ }^{39,44}$ Santos e colaboradores verificaram a correlação entre os métodos de FPS in vivo (FDA) $)^{39}$ e in vitro (Mansur). ${ }^{44}$ Os resultados mostraram uma boa correlação nos ensaios de FPS in vitro obtidos para o homosalato a $8 \%$ (FPS 5,0 in vivo) e para o metóxicinamato de 2-etilexila (metóxicinamato de octila; OMC) a 7,5 \% (FPS 15,8 in vivo), os quais apresentaram valores de FPS 5,0 e 15,3, respectivamente, para os ensaios in vitro. ${ }^{46}$

$$
\begin{gathered}
\text { FPS espectrofotométrico }=F C . \sum_{290}^{320} E E(\lambda) . I(\lambda) . \text { Abs }(\lambda) \\
F C=10(\text { FPS } 4 \text { em homosalato a } 8 \%) \quad I=\text { Intensidade do sol } \\
\text { EE = Efeito Eritemogênico } \quad A b s=\text { Absorbância da amostra }
\end{gathered}
$$

Tabela 5. Influência na ocorrência de eritemas frente a absorção UVB ${ }^{44,45}$

\begin{tabular}{cc}
\hline UVB (nm) & EE x I (normalizado) \\
\hline 290 & 0,0150 \\
295 & 0,0817 \\
300 & 0,2874 \\
305 & 0,3278 \\
310 & 0,1864 \\
315 & 0,0839 \\
320 & 0,0180 \\
\hline$E E=$ Efeito Eritemogênico; I = Intensidade do sol
\end{tabular}

Recentemente, em 2011, Velasco e colaboradores revisaram as metodologias analíticas empregadas na avaliação in vitro dos fotoprotetores, onde também foi destacada a importância na determinação da eficácia fotoprotetora UVB via transmitância difusa. ${ }^{37}$ Neste método, a intensidade da luz que incide nos fotoprotetores ocorre de 
acordo com uma distribuição hemisférica. A transmitância hemisférica total pode ser mensurada pelo emprego de uma esfera de integração que captura a luz dispersa em todos os ângulos. Entretanto, é reportado também que a maior aplicação deste método se dá na determinação do FPS de formulações que contenham filtros solares inorgânicos. ${ }^{37,40}$

O valor do fator de proteção UVA (FPUVA) é conseguido, in vivo, pela razão entre a dose mínima pigmentária (DMP) numa pele fotoprotegida e a pele fotodesprotegida (Equação 3). É compreendida como DMP a radiação UVA necessária para promover o escurecimento pigmentário natural cutâneo observado entre 2 e 4 horas após a exposição à radiação UVA simulada $\left(15 \mathrm{~J} / \mathrm{cm}^{2}\right) \cdot{ }^{36,37} \mathrm{O}$ método para obtenção do valor de FP-UVA in vitro consiste na absorção do comprimento de onda crítico $\left(\lambda_{c}\right)$. O $\lambda_{c}$ é aquele abaixo do qual $90 \%$ da absorção UV pelo fotoprotetor acontece no intervalo de 290 a $400 \mathrm{~nm}$. Assim, por exemplo, um protetor solar de $\lambda_{C}$ igual a $340 \mathrm{~nm}$ será eficaz contra UVB e UVAII, mas não contra UVA-I, que está compreendida entre 340 e $400 \mathrm{~nm} \cdot{ }^{12,37,47}$ Outros médodos que também mensuram a proteção UVA são o Índice UVA e a Proporção UVA-I/UV. Tanto o método via $\lambda_{c}$ quanto os métodos baseados na análise da difusão da transmitância (Índice UVA e Proporção UVAI/UV) são classificados quanto aos seus intervalos escalonados (Tabela 6). Muito embora estes métodos de avaliação do fator UVA sejam recentes, suas metologias requerem aprimoramentos. Isto pode ser visto na existência de resultados conflitantes, como por exemplo, uma mistura contendo 3,5 \% de 4-metóxicinamato de 2-etilexila (OMC) e $1,0 \%$ de 2-hidróxi-4metóxibenzofenona (BZF-3) foi classificada como anti-UVA 'alto' quando analisada pelos métodos de $\lambda_{c}(359 \mathrm{~nm})$ e Proporção UVAI/UV $(0,73)$, porém ordenada como fator antiUVA 'médio' via Índice UVA $(0,44) \cdot{ }^{39,48,49}$ Os filtros solares comerciais UVB e UVA, especificados na rotulagem, devem ter no mínimo $33 \%$ de proteção UVA em relação ao FPS UVB indicado e, além disso, o $\lambda_{C}$ mínimo deve absorver em $370 \mathrm{~nm} \cdot{ }^{2,13,39}$ A proteção UVA dos produtos fotoprotetores pode ainda ser verificada pela presença de estrelas gravadas nos rótulos dos produtos, onde, o maior número destas equivale a uma maior proteção contra os raios UVA. ${ }^{12,37}$

$$
F P-U V A=\frac{D M P(\text { na pele fotoprotegida })}{D M P(\text { na pele fotodesprotegida })}
$$

Tabela 6. Categorias dos métodos de avaliação do fator de proteção UVA in vitro. ${ }^{48}$

\begin{tabular}{ccccc}
\hline $\begin{array}{c}\text { Fator de proteção UVA in vitro } \\
\lambda_{C}(\mathrm{~nm})\end{array}$ & Baixo & Médio & Alto & Muito alto \\
$\begin{array}{c}\text { Índice UVA e } \\
\text { Proporção UVA-I/UV }\end{array}$ & $325-335$ & $335-350$ & $350-370$ & $>370$ \\
& $0,20-0,39$ & $0,40-0,69$ & $0,70-0,95$ & $>0,95$ \\
\hline
\end{tabular}

Estudos atuais mostram que a pigmentação cutânea pode ser causada tanto pelos raios UVA quanto pela radiação VIS. ${ }^{50}$ Em 2012, Schalka e colaboradores reportaram a importância da proteção também contra os raios VIS, pois estes são responsáveis pela produção de $33 \%$ das EROs geradas no estrato córneo. Os ensaios realizados frente à luz VIS na faixa do azul (400 a $450 \mathrm{~nm}$ ), região mais energética, apontam para uma maior fotoproteção dos produtos coloridos frente aos produtos brancos. Contudo, os resultados não apresentaram correlação com os valores de FPS dos produtos avaliados frente à absorção na luz VIS. ${ }^{51}$ 


\section{Fotoprotetores Orgânicos}

As estruturas moleculares dos fotoprotetores orgânicos apresentam, muito comumente, anéis benzênicos contendo pelo menos dois grupos subtituintes nas posições orto ou para, sendo um grupo doador de elétrons e o outro um elétron-atrator. São substituíntes que atribuem um efeito batocrômico pela extensão da conjugação e absorvem na região de interesse do UV., ${ }^{6,11} \mathrm{O}$ ácido $p$-aminobenzoico (PABA) ( $\mathbf{A}$ - Figura 2 ) é um filtro UVB clássico, patenteado em
$1943,{ }^{5}$ e que apresenta este padrão. Outra característica importante é a inserção de cadeias alquílicas para contribuir na lipofilia molecular, pois aumenta a adesão da substância à pele evitando sua retirada pela ação da água. Um derivado do PABA, o 4dimetilaminobenzoato de 2-etilexila (padimato O) (B - Figura 2) possui esta alteração estrutural. Neste caso, além da melhoria lipofílica, também foi obtido um deslocamento batocrômico, pois o PABA tem uma absorção máxima $\left(\lambda_{\max }\right)$ em $283 \mathrm{~nm}$ enquanto o padimato $\mathrm{O}$ absorve em 307 nm. ${ }^{11}$<smiles>Nc1ccc(C(=O)O)cc1</smiles><smiles>CCCCC(CC)COC(=O)c1ccc(N(C)C)cc1</smiles>

Figura 2. Ácido $p$-aminobenzoico (PABA) (A); 4-dimetilaminobenzoato de 2-etilexila (padimato O) $(B)^{11}$

A natureza do grupo substuinte na posição orto pode conferir um efeito batocrômico em função da possibilidade de ligação de hidrogênio intramolecular. ${ }^{11}$ Estas substâncias absorvem em maiores comprimentos de onda, pois sua ressonância é facilitada pela disponibilidade eletrônica. ${ }^{16}$
Isto pode ser visto no caso dos parabenos (A - Figura 3), ésteres benzoicos $p$-hidroxilados, que absorvem próximos de $260 \mathrm{~nm}$ e seus isômeros, os salicilatos (B - Figura 3), que são ésteres benzoicos $O$-hidroxilados, absorvem UV em $300 \mathrm{~nm} .{ }^{11}$

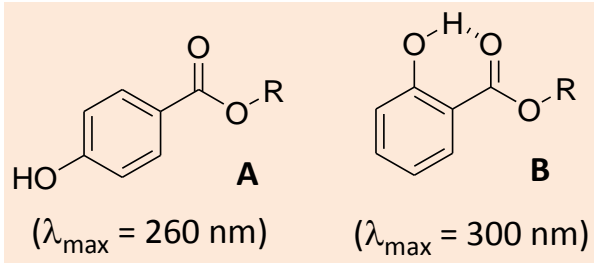

Figura 3. Parabenos (A) e salicilatos (B) $)^{11}$

As moléculas que possuem estas especificações absorvem os raios UV danosos à pele (UVB-UVA) transformando-os em ondas eletromagnéticas da região do VIS ou IV, inofensivas aos seres humanos. ${ }^{11} \mathrm{O}$ mecanismo de ação consiste na transição eletrônica dos estados estáveis do orbital molecular não ligante $n$ ou do orbital ligante $\pi$, ou seja, do orbital ocupado de maior energia (HOMO), para o estado excitado $\pi^{*}$ do orbital desocupado de menor energia (LUMO). Durante o retorno do elétron do orbital antiligante ao estado fundamental, $\pi^{*} \rightarrow n$ ou $\pi^{*} \rightarrow \pi$, ocorre a liberação de menor quantidade de energia sob a forma de ondas eletromagnéticas com comprimentos 
de onda acima de $400 \mathrm{~nm}$ (Figura 4). ${ }^{6,11}$ A radiação UV absorvida tem energia exatamente igual à diferença de energia entre os estados fundamental e excitado.
Assim, uma transição $\pi \rightarrow \pi^{*}$ processa bem mais energia do UV quando comparada à transição $n \rightarrow \pi^{*}$. ${ }^{16,52}$

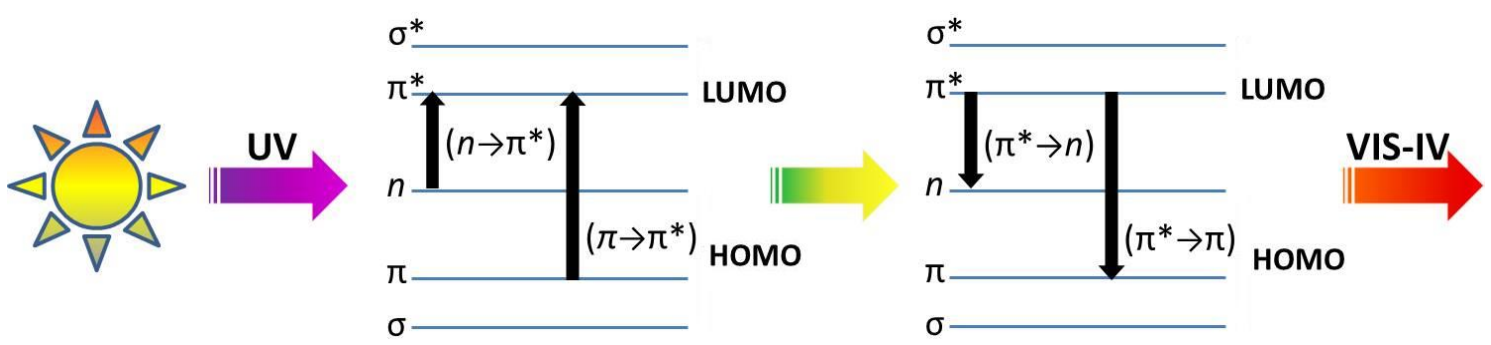

Figura 4. Transição eletrônica das radiações UV e conversão em VIS e IV pelo fotoprotetores orgânicos. Adaptado de Balzani, Pavia e Shaath ${ }^{11,16,52}$

De acordo com a estrutura molecular dos fotoprotetores orgânicos estes podem ser classificados principalmente como fotoestável ou fotolábil. ${ }^{11,53} \mathrm{~A}$ isomeria $E / Z$, quando a radiação incidente é não destrutiva à estrutura molecular, fornece fotoprotetores orgânicos do tipo fluorescentes, fosforescentes ou de isomerização reversível. Estas moléculas são consideradas fotoestáveis e dissipam a energia processada durante a fotoisomerização. ${ }^{11} \quad 0$ metóxicinamato de octila (OMC), ${ }^{54}$ que é um filtro comercial empregado mundialmente em cerca de $90 \%$ dos produtos para proteção solar, possui esta forma de ação (Figura 5). ${ }^{5,11,55}$ Isto ocorre quando o isômero
$E(A)$ absorve radiação UV e é convertido ao isômero $Z(B)$, mais energético. Durante o retorno a configuração mais estável (A), há liberação de radiação IV e VIS neste processo que é contínuo. No entanto, a sua fotoisomerização é amplamente investigada ${ }^{53,55,56}$ e alguns resultados apontam uma perda de fotoproteção de até $38 \%$ dependendo dos constituintes da preparação cosmética do filtro solar. ${ }^{57} \mathrm{~A}$ fotoinstabilidade do OMC é ratificada através de estudos atuais, os quais reportam sua degradação tanto pela ciclodimerização quanto pela formação de derivados citotóxicos via fotólise em meio aquoso. ${ }^{58}$

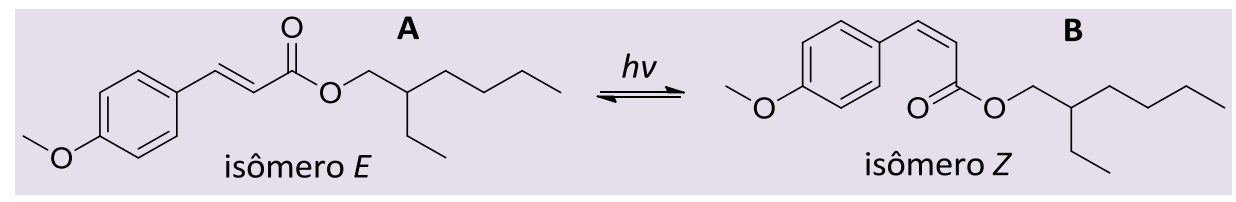

Figura 5. Fotoisomerização do $O M C^{55}$

A importância do grupamento cinâmico na fotoproteção do OMC pode ser vista nos espectros de UV apresentados na Figura 6. De acordo com estes espectros, tanto o OMC (A) quanto o 4-metoxicinamaldeído (B), ambos numa concentração molar de $1 \times 10^{-5}$ $\mathrm{mol} / \mathrm{L}$ em $\mathrm{CH}_{2} \mathrm{Cl}_{2}$, apresentaram valores bem próximos de absorção UVB, $\lambda_{\max } 309$ e 318 $\mathrm{nm})$, respectivamente. 

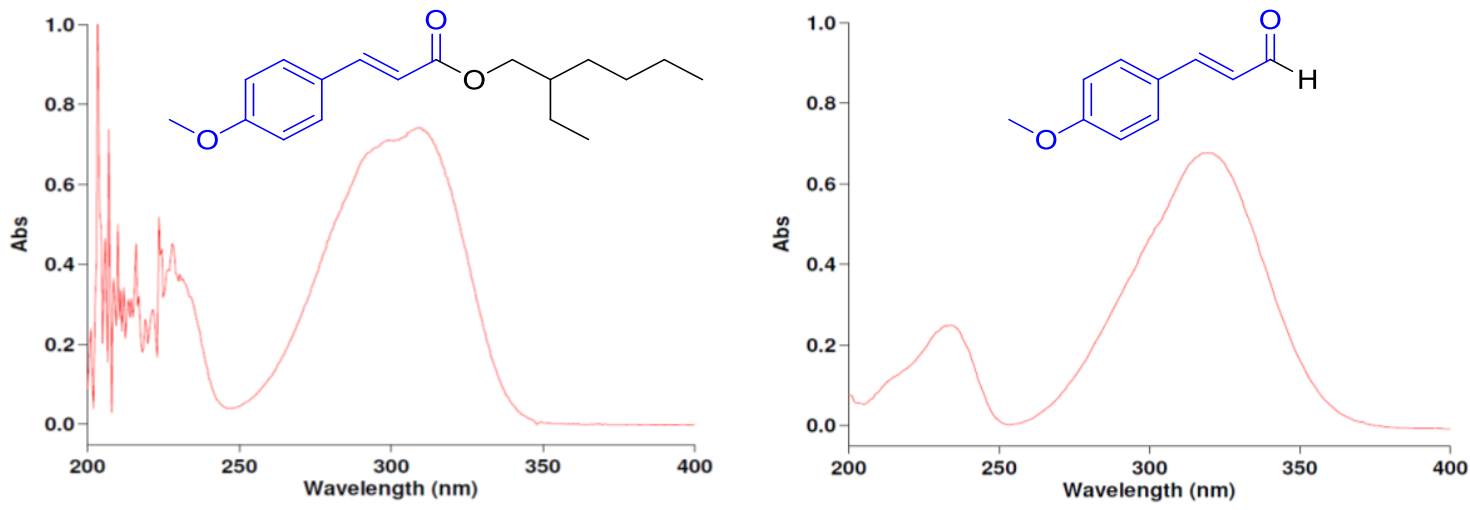

Figura 6. Espectros de UV do OMC (A) e do 4-metoxicinamaldeído (B), ambos a $1 \times 10^{-5} \mathrm{M}$ em $\mathrm{CH}_{2} \mathrm{Cl}_{2}$.Espectros das análises de UV feitas por Luciano Freitas do Nascimento

Uma molécula que sofre tautomerismo do tipo ceto-enol pode ser classificada como um protetor solar fotolábil. ${ }^{11}$ Isto pode ser verificado no caso do 1-(4-t-butilfenil)-3-(4metóxifenil)-1,3-propadiona (avobenzona) (Figura 7) que é um dos poucos filtros UVA-I comercialmente disponível. ${ }^{5}$ A ressonância facilitada pela disponibilidade eletrônica ${ }^{16}$ do tautômero enólico (B) o torna mais estável do que o tautômero cetônico (A). Isto é confirmado pela diferença na absorção da radiação UV destes tautômeros ceto-enólicos que absorvem em $\lambda_{\max } 260 \mathrm{~nm}$ (A) e $357 \mathrm{~nm}$ (B), respectivamente. ${ }^{11}$

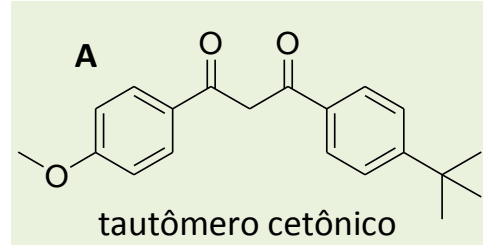

Figura 7. Tautomerismo ceto-enólico da avobenzona ${ }^{11}$
Além dos aspectos estruturais, os fotoprotetores orgânicos UV ideais devem preconizar outras diversas características. São elas: (a) estabilidade a luz, ao calor e a água; (b) não deve ser tóxico, irritante, mutagênico ou teratogênico, com ou sem a ação da luz; (c) absorver UV em amplo espectro (UVA e UVB); (d) possuir um coeficiente de extinção específica $\left(E_{1 \%}, 1 \mathrm{~cm}\right)$ acima de 1.000 para se ter o máximo de proteção com o mínimo emprego de filtro UV; (e) apresentar um peso molecular superior a 500 Daltons (D) para se prevenir a permeação cutânea; (f) possuir um log $\mathrm{P}$ (coeficiente de partição entre água e octanol) superior a 5 , ou seja, deve possuir uma lipofilia específica para uma boa adesão a pela, sem que ocorra a sua retirada pela ação da água e evitando também a permeabilidade cutânea por afinidade ao tecido córneo e (g) não deve apesentar sinergia com outros componentes da formulação de um filtro solar, ou mesmo com a embalagem de acondicionamento do produto acabado. ${ }^{10,11,59,60}$ Todavia, mesmo não cumprindo exatamente todas estas condições prévias, muitas substâncias orgânicas são empregadas comercialmente como agentes de fotoproteção UV. ${ }^{55}$ 


\subsection{Fotoprotetores orgânicos comerciais}

Diversas agências mundiais regulamentam o uso dos filtros solares comerciais, tais como a FDA nos Estados Unidos, a COLIPA (Commitee de Liaison des Associations Europeans de L'Industries de la Parfumerie, de Produits Cosmetiques et de Toilette) na Europa, a JCIA (Japan Cosmetic Industry Association) no Japão, a TGA (Therapeutic Goods Act) na Austrália e Nova Zelândia e o MERCOSUL na Argentina, Brasil, Paraguai e Uruguai. $^{11}$ No Brasil, a ANVISA, em consonância com o MERCOSUL, disponibiliza o Regulamento Técnico que versa sobre a "Lista de filtros ultravioletas permitidos para produtos de higiene pessoal, cosméticos e perfumes". Este documento correlaciona 38 substâncias com suas respectivas concentrações máximas de dosagem, onde, destas, 36 são compostos orgânicos. ${ }^{36}$

Uma observação de suma importância é a confusão decorrente do emprego de diversos nomes para uma única substância fotoprotetora comercial. A utilização das nomenclaturas IUPAC, INCl, USAN, além dos muitos nomes comerciais, é, no mínimo, um incômodo para os profissionais e cientistas deste segmento. Isto pode ser verificado no caso do 4metóxicinamato de 2-etilexila (Tabela 7). ${ }^{11}$

Tabela 7. Nomenclaturas utilizadas para uma mesma substância ${ }^{11}$

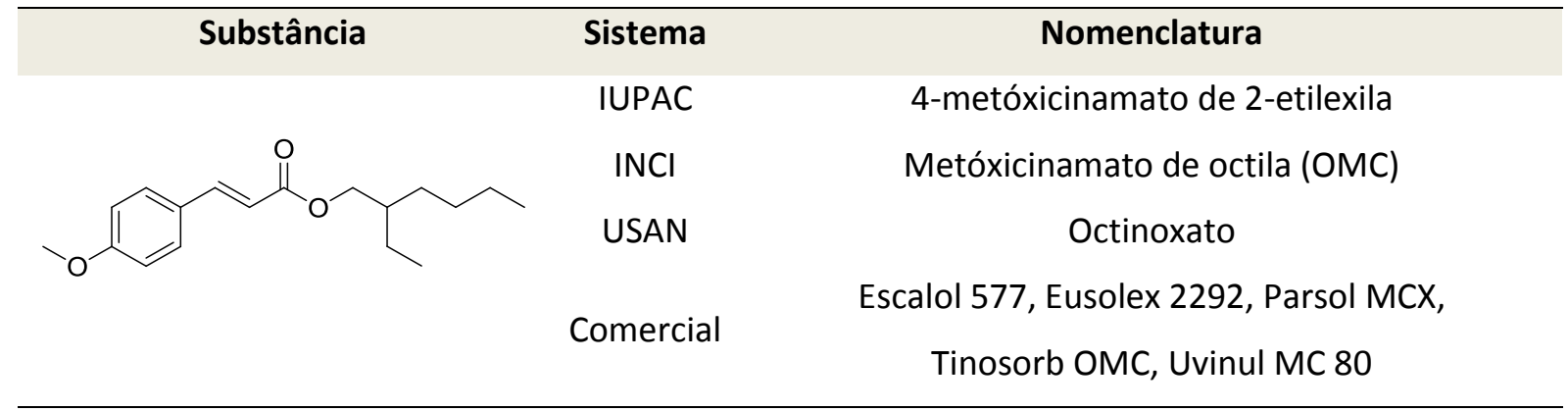

A derivatização de fotoprotetores mais antigos a fim de obter moléculas mais ativas é uma prática comum dentre as substâncias comercializadas. ${ }^{5}$ A benzofenona (BZF) pode ser sintetizada via reações de alquilação de Friedel-Crafts entre benzeno e tetracloreto de carbono, na presença de $\mathrm{AlCl}_{3}$, com posterior hidratação. ${ }^{61}$ Esta substância fornece boa fotoproteção UVB-UVA (284-340 $\mathrm{nm}$ ), muito embora seu uso seja proibido em função de seu poder de irritação dérmica e ocular. Ainda assim, a BZF foi pioneira no alcance de muitos derivados (A-H) aprimorados (Figura 8). A inserção de uma variedade de grupos cromofóricos a essas novas moléculas produziu diversos efeitos positivos, tais como a perda do poder irritante a pele e aos olhos na BZF-1 (2,4-dihidróxibenzofenona; $A)$, na BZF-2 $\left(2,2^{\prime}, 4,4^{\prime}-\right.$ tetrahidróxibenzofenona; B), na BZF-5 (5benzoil-4-hidróxi-2-metóxibenzenossulfonato de sódio; E), na BZF-6 (2,2'-dihidróxi-4,4'dimetóxibenzofenona; F) e na BZF-9 (3,3'carbonil-bis[4-hidróxi-6-

metóxibenzenossulfonato de sódio]; $\mathbf{H}$ ); a não mutagenicidade na BZF-2 e na BZF-9, além do alto peso molecular da BZF-9 $(478,36$ $\mathrm{g} / \mathrm{mol}) .{ }^{11,55}$ 
<smiles>COc1ccccc1C(=O)c1cccc(OC)c1OC(=O)c1cccc(OC)c1O</smiles>

Figura 8. Derivados da benzofenona (BZF) $)^{11}$

Em geral, quase todas as substâncias fotoprotetoras comerciais são oriundas de classes mais simples de moléculas absorvedoras de UV, como no caso dos derivados do PABA, salicilatos, cinamatos e do benzilideno cânfora (Tabela 8). ${ }^{5}$ Como exemplos de melhorias, os derivados 4dimetilaminobenzoato de pentila (padimato
A) e o 3-benzilideno cânfora não apresentam irritação cutânea e ocular, enquanto o salicilato de 3,3,5-trimetilcicloexila (homosalato) e o 2-ciano-3,3difenilpropenoato de 2-etilexila (octocrileno), além de não irritantes, não apresentam atividades mutagênicas. ${ }^{11,55}$

Tabela 8. Derivados comerciais do PABA, salicilatos, cinamatos e benzilideno cânfora ${ }^{5,11}$

\begin{tabular}{|c|c|c|}
\hline Classes & Derivados & $\lambda_{\max }(\mathrm{nm})$ \\
\hline \multirow[b]{5}{*}{ PABA } & 4-dimetilaminobenzoato de pentila & 310 \\
\hline & 4-dimetilaminobenzoato de 2-etilexila & 311 \\
\hline & 4-aminobenzoato de 2,3-dihidróxipropila & 297 \\
\hline & 4-bis(2-hidróxipropil)aminobenzoato de etila & 312 \\
\hline & 4-bis(polietóxi)aminobenzoato de polietóxietila & 309 \\
\hline \multirow[b]{4}{*}{ Salicilato } & Salicilato de 2-etilexila & 305 \\
\hline & Salicilato de 3,3,5-trimetilcicloexila & 306 \\
\hline & 4-isopropilsalicilato de benzila & 310 \\
\hline & Salicilato de $2,2^{\prime}, 2^{\prime \prime}$-triidróxitrietilamônio & 298 \\
\hline \multirow[b]{5}{*}{ Cinamato } & 4-metóxicinamato de 3-metilbutila & 308 \\
\hline & 4-metóxicinamato de 2-etilexila & 311 \\
\hline & 4-metóxicinamato de 2-etóxietila & 308 \\
\hline & 4-metóxicinamato de 2,2'-di-hidróxidietilamônio & 290 \\
\hline & 2-ciano-3,3-difenilpropenoato de 2-etilexila & 303 \\
\hline \multirow[b]{4}{*}{$\begin{array}{c}\text { O } \\
\text { Benzilideno cânfora }\end{array}$} & 3-benzilideno cânfora & 294 \\
\hline & 3-(4-metilbenzilideno) cânfora & 300 \\
\hline & 3-(4-sulfobenzilideno) cânfora & 294 \\
\hline & Metilssulfato de 3-(4-trimetilamôniobenzilideno) & 284 \\
\hline
\end{tabular}

Alguns dos problemas mais comuns nos fotoprotetores orgânicos comerciais são a fotoinstabilidade, ${ }^{49,55}$ com consequente decaimento fotoprotetor, e um espectro específico de fotoproteção UVA ou UVB. Neste aspecto, um componente pode apresentar um comportamento fotoprotetor adequado em apenas uma das regiões (UVA 
ou UVB). Uma solução alternativa para estes casos foi o emprego de combinações de moléculas fotoprotetoras nos filtros solares. ${ }^{5,12}$ A empresa Neutrogena patenteou uma associação de filtros UV, que combina a avobenzona (Figura 7) com a oxibenzona (Figura 8C), chamada comercialmente de Helioplex $^{\circledast}$. O filtro solar contendo esses produtos fornece proteção UVA e UVB por mais tempo do que estes ativos aplicados separadamente. Essa combinação reduz a fotodegradação da avobenzona impedindo, portanto, a ocorrência de dermatites solares por um maior tempo de exposição. ${ }^{12}$ No Brasil são comercializadas 31 diferentes associações, dentre as quais, a BZF com o OMC e a oxibenzona com o padimato $0 .{ }^{18}$ Todavia, esta prática necessita de investigações contínuas relacionadas à fotoestabilidade..$^{5,53,55,62,63} \quad$ Muito recentemente, em 2012, Santos e colaboradores revisaram os aspectos da fotodegradação dos protetores solares orgânicos mais utilizados, bem como o impacto dos seus derivados fotodegradados ao meio ambiente. ${ }^{55}$

Outro problema que requer grande atenção é a permeabilidade cutânea apresentada por muitos fotoprotetores comerciais. Hayden e colaboradores investigaram a permeabilidade dos filtros avobenzona, padimato $\mathrm{O}$, octinoxato, octocrileno e oxibenzona após aplicação tópica destes sobre o extrato córneo. Todas as substâncias apresentaram penetração epidérmica com uma maior evidência para a oxibenzona. ${ }^{64}$ Este fotoprotetor comercial também foi detectado em amostras de urina em ensaios com voluntários humanos. ${ }^{65} \mathrm{Em}$ 2011, o emprego da técnica de cromatografia líquida de alta eficiência (CLAE) em fase reversa na avaliação da permeabilidade cutânea mostrou que a BZF-3 ( $\log$ P 3,58$)$ possui boa habilidade de penetração na pele quando comparada ao OMC $(\log P 5,96)$ e ao octilsalicilato (Log $P$ 6,02). ${ }^{66}$ Wosicka e Cal revisaram os estudos sobre a passagem de substâncias de uso tópico através do folículo piloso. Compostos da ordem de até $40 \mathrm{~nm}$ transpassam a barreira dérmica via esse caminho. ${ }^{67}$

Estudos atuais também reportam a possibilidade da ocorrência de melanomas pela ação dos núcleos benzênicos de alguns fotoprotetores orgânicos comerciais na síntese da melanina decorrente na região dérmica, ${ }^{68}$ bem como a adição coadjuvante de antioxidantes nas formulações cosméticas para neutralizar as EROs epidérmicas. ${ }^{69}$

Uma classe especial de filtros orgânicos possui dupla ação em função de suas características físicas, pois agem tanto via absorção quanto através da reflexão dos raios UV. Estes compostos patenteados possuem estruturas de alto peso molecular, apresentam amplo espectro de fotoproteção e cumprem bem os pré-requisitos para um filtro orgânico UV ideal (Tabela 9). ${ }^{11}$

Tabela 9. Fotoprotetores orgânicos patenteados ${ }^{11}$

\begin{tabular}{cccccc}
\hline Nomenclatura* & $\begin{array}{c}\text { Nome } \\
\text { comercial }\end{array}$ & Fabricante & $\begin{array}{c}\text { Peso } \\
\text { (D) }\end{array}$ & $\begin{array}{c}\boldsymbol{\lambda}_{\max }(\mathbf{n m}) / \\
\text { E (1 \%, 1 cm) }\end{array}$ & UV \\
\hline $\begin{array}{c}\text { 2,2'-metileno-bis[6-(2H-2-benzotriazoil)-4- } \\
\text { (1,1,3,3-tetrametilbutil)fenol] }\end{array}$ & Tinosorb M & Ciba & 658 & $\begin{array}{c}305 / 404 \\
360 / 495\end{array}$ & UVB \\
\hline $\begin{array}{c}\text { 2-(2H-2-benzotriazoil)-4-metil-6-\{2-metil- } \\
\text { 3-[1,3,3,3-tetrametil-1- } \\
\text { (trimetilsilil)óxidisiloxanil]propil\} }\end{array}$ & Mexoryl XL & L'Oréal & 501 & $303 / 309$ & UVB \\
\hline $\begin{array}{c}\text { 2,4-bis\{[4-(2-etilexil-óxi)-2-hidróxi]fenil\}-6- } \\
\text { (4-metóxifenil)-1,3,5-triazina }\end{array}$ & Tinosorb S & Ciba & 629 & $310 / 745$ & UVB \\
\hline
\end{tabular}




\begin{tabular}{|c|c|c|c|c|c|}
\hline $\begin{array}{c}\text { 2,4,6-trianilínio-4-(carbo-2'-etilexíl-1'-óxi)- } \\
\text { 1,3,5-triazina }\end{array}$ & Uvinul T150 & BASF & 823 & 314 / 1450 & UVB \\
\hline $\begin{array}{c}\text { 3,3'-[[6-(\{4-[(t-butilamino)carbonil]fenil\} } \\
\text { amino)-1,3,5-triazina-2,4-diil]di(imino })] \\
\text { dibenzoato de bis(2-etilexila) }\end{array}$ & Uvasorb HEB & 3V-Sigma & 766 & 312 / 1460 & UVB \\
\hline $\begin{array}{l}\text { Sal dissódico do ácido 2,2'-bis(1,4- } \\
\text { fenileno)-1H-benzimidazol-4,6-dissulfônico }\end{array}$ & $\begin{array}{l}\text { Neo Heliopan } \\
\text { AP }\end{array}$ & Symrise & 675 & 334 / 775 & UVA \\
\hline $\begin{array}{l}\text { 3,3'-(1,4-fenilenodimetileno)- } \\
\text { bis[7,7dimetil-oxabiciclo[2.2.1]-1- } \\
\text { heptilmetanossulfonato de sódio] }\end{array}$ & Mexoryl SX & L’Oréal & 607 & 345 / 775 & UVA \\
\hline $\begin{array}{l}\text { 2-[4-(dietilamino)-2- } \\
\text { hidróxibenzoil]benzoato de hexila }\end{array}$ & Uvinul A Plus & BASF & 398 & 354 / 900 & UVA \\
\hline $\begin{array}{l}N^{2}, N^{4} \text {-bis }\{4-[5-(1,1-\text { dimetilbutil)-1,3-2- } \\
\text { benzoxazoil]fenil\}- } N^{6} \text {-(2-etilexil)-1,3,5- } \\
\text { triazina-2,4,6-triamina }\end{array}$ & Uvasorb K2A & 3V-Sigma & 760 & 338 / 405 & UVA \\
\hline
\end{tabular}

2.2. Pesquisa e inovação em
fotoprotetores orgânicos

Um significante parâmetro da pesquisa e da inovação em novos protetores UV é o registro de patentes, tendo em vista a sua importância e, certamente, os interesses comerciais. Os registros são decorrentes tanto de trabalhos voltados para o desenvolvimento de novas formulações e de associações de filtros comerciais, quanto na pesquisa de novas moléculas fotoprotetoras. $^{18}$

A primeira substância patenteada foi a avobenzona (Figura 7), em 1980, nos Estados Unidos, pela empresa New Drug Apllication e era de uso exclusivo da californiana Herbert Laboratories. Grandes companhias como a BASF, Ciba, Merck e L'Oréal depositam frequentemente novas patentes. ${ }^{11} \mathrm{~A}$ análise geral de 111 patentes depositadas entre 1980 e 2008 evidenciou que apenas $3 \%$ das solicitações são voltadas para a pequisa de novos ativos. Restringindo a depósitos nacionais, através do Instituto Nacional de Propriedade Intelectual (INPI), foram verificados 32 documentos e estes apontaram um total de $12 \%$ desta frente de trabalho (Tabela 10). ${ }^{18}$ Com base nestes dados, a pesquisa de novas moléculas fotoprotetoras se torna um vasto campo de atuação científica.

Tabela 10. Depósitos de patentes no segmento de fotoproteção ${ }^{18}$

\begin{tabular}{ccccc}
\hline \multirow{2}{*}{ Fonte } & \multicolumn{4}{c}{ Tipos de inovações depositadas } \\
& Formulações (\%) & Associações (\%) & Novos ativos (\%) & Outros (\%) \\
Geral* & 84 & 10 & 03 & 03 \\
INPI & 63 & 19 & 12 & 06 \\
\hline
\end{tabular}

* Dados sistematizados no SciFinder Scholar 2007 por Guaratini e colaboradores ${ }^{18}$ 


\subsubsection{Fotoprotetores orgânicos naturais}

Diversas classes de substâncias naturais foram investigadas quanto às suas atividades antioxidantes e fotoprotetoras (Figura 9). ${ }^{18,24,27,28,70-72}$ Polonini e colaboradores revisaram recentemente, em 2011, a importância dos fotoprotetores naturais nas composições dos filtros solares comerciais e a consequente prevenção do câncer de pele. ${ }^{73}$ Todavia, estes agentes orgânicos naturais apresentam, frequentemente, fotoproteção muito inferior às empregadas especificamente para este fim. ${ }^{36}$ Assim, o seu uso se faz principalmente no intuito de contribuir, ou seja, um coadjuvante com os agentes próprios para fotoproteção em uma formulação de filtro solar. ${ }^{18,70,71}$

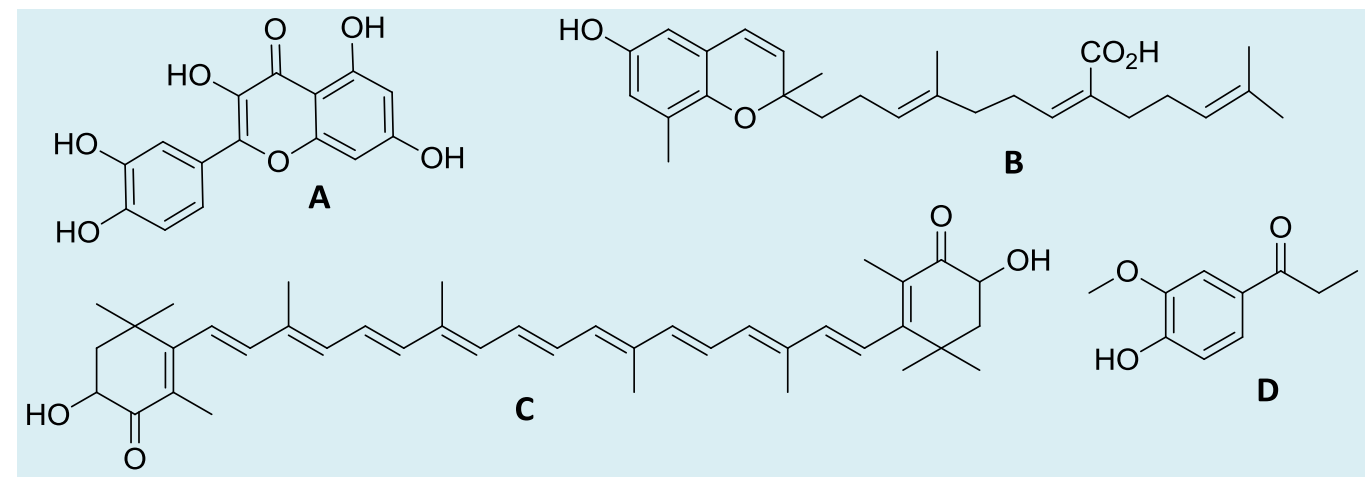

Figura 9. Flavonoides (A), tocotrienois (B), carotenoides (C) e propiofenonas (D) ${ }^{18}$

As propriedades fotoprotetoras também foram avaliadas em extratos de uma grande variedade de plantas. $\mathrm{Hu}$ e Wang empregaram uma mistura contendo extratos de Chrysanthemum ramat e Crocus sativus (L) frente ao ácido 2-hidróxi-4metóxibenzofenona-5-sulfônico (BZF-4) e constataram um resultado melhor quanto ao tempo relacionado no desaparecimento do eritema induzido. No entanto, para isso, a mistura de extratos foi empregada numa concentração quatro vezes superior a da BZF4 para se conseguir resultados semelhentes de proteção UV. ${ }^{74}$

Em 2009, Violante e colaboradores avaliaram a atividade fotoprotetora em extratos vegetais provenientes do cerrado de Mato Grosso. Os extratos das espécies estudadas (Microsiphonia velame, Oxalis hirsutissima e Lafoensia pacari) apresentaram absorção no UV em $\lambda_{\max } 318$ $\mathrm{nm}, 324 \mathrm{~nm}$ e $356 \mathrm{~nm}$, respectivamente. Os ensaios fitoquímicos qualitativos evidenciaram a presença de alcaloides, flavonoides e taninos, que são substâncias naturalmente fotoprotetoras. Entretanto, a avaliação do FPS in vitro da $M$. velame (absorvedor UVB) apresentou FPS 0,36 enquanto o OMC forneceu um FPS 13,21, ambos em mesma concentração $(7,5 \%){ }^{71}$

Said e colaboradores reportaram interessantes resultados de fotoproteção UVA e UVB para o extrato de Calophyllum inophyllum. Este extrato oleoso além de ter aproximadamente $71 \%$ de ácidos graxos é rico em diversos compostos fotoprotetores naturais, como biflavonoides, tocoferóis e tocotrienois. Somado a uma ampla absorbância UV, de 250 a 400 nm (UVA-UVB; $\lambda_{\max } 300 \mathrm{~nm}$ ), os resultados mostraram atividade antioxidante, sendo não citotóxico e não irritante, como também a significante redução da produção de EROs. ${ }^{28}$

Uma linha de pesquisa digna de grande atenção é a dos fotoprotetores biológicos naturais. Estas substâncias são fotosintetizadas durante a ação dos raios UV nas células de determinados microorganismos como as cianobactérias, fitoplânctons, microalgas ${ }^{75}$ e moluscos. ${ }^{76}$ Recentes revisões, 2011, discutem a natureza destes metabólicos secundários, citonemina 
e micosporina, presentes nestes organismos, bem como a fotoproteção das suas organelas contra os raios deletéricos UV. ${ }^{77,78}$

Conforme descrito, os estudos em produtos naturais que preconizam atividades de proteção contra os raios UV apresentam um amplo potencial na pesquisa de fotoprotetores. Todavia, a síntese orgânica, racional e estratégica, conduz a um promissor caminho para a obtenção de novas substâncias fotoprotetoras ideais.

\subsubsection{Síntese de novos fotoprotetores} orgânicos

A importância da síntese orgânica na obtenção de novos compostos farmacológicos corretivos ou preventivos pode ser constatada no fato de que $79 \%$ dos fármacos comercializados são de origem sintética. ${ }^{79}$ Assim sendo, a síntese orgânica racionalizada pode trazer contribuições relevantes no desenvolvido de novos fotoprotetores orgânicos ideais e mais acessíveis. $^{4,59}$ Freitas e colaboradores aplicaram esse princípio para sintetizar novas moléculas fotoprotetoras que apresentaram resultados vantajosos e motivadores frente à hidrólise enzimática, conseguindo, portanto, maior adesão da substância ao extrato córneo e aumentando o seu tempo de retenção à pele. ${ }^{80}$

Atualmente, muitos compostos orgânicos foram desenvolvidos e avaliados quando às suas propriedades fotoprotetoras. ${ }^{7}$ Reagindo um oxabiciclo apropriado com diversos alcóxi-benzaldeídos via condensação aldólica, ${ }^{81}$ na presença de $\mathrm{NaOCH}_{3}$, Mariani e colaboradores obtiveram uma série de novos potenciais filtros solares orgânicos (Figura 10). Estes derivados foram avaliados quanto a capacidade de absorção de UV através dos valores do índice de fotoproteção, além de ensaios in vitro de fotoxidade e permeação cutânea. ${ }^{82}$ Algumas substâncias (A-B) apresentaram características fotoprotetoras UVA ideais como absorção em ampla faixa do espectro, além da não permeação no tecido cutâneo e da fototoxicidade aceitável, quando comparadas ao filtro comercial 3-(4metilbenzilideno) cânfora. ${ }^{82}$

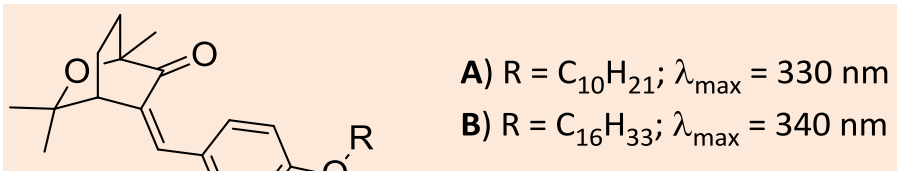

Figura 10. Potenciais fotoprotetores orgânicos sintetizados por Mariani e colaboradores ${ }^{82}$

Um trabalho acadêmico reportou a fotoprotetor foi preparado via acilação de síntese do ácido 2-(2',4'- Friedel-Crafts ${ }^{81}$ entre $m$-xileno e anidrido dimetilbenzoil)benzoico, derivado da ftálico, na presença de $\mathrm{AlCl}_{3}$ e com posterior benzofenona (Figura 11) ${ }^{83}$ Este candidato a tratamento ácido. ${ }^{83}$

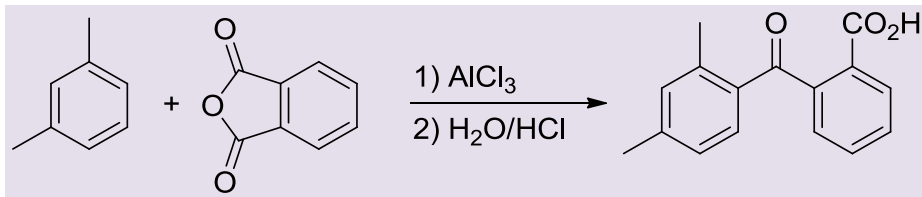

Figura 11. Reações de formação do protótipo derivado da BZF ${ }^{83}$ 
Tridentatóis, $N$-[(dialquiltio) metileno], são derivados de tiraminas conjugadas que possuem potencial atividade fotoprotetora. Estas substâncias são isoladas do hidroide marinho Tridentata marginata. Contudo, a síntese de diversos análogos forneceu novas substâncias absorvedoras em $\lambda_{\max } 334 \mathrm{~nm}$ (Figura 12). A pouca citotoxicidade destes produtos nos ensaios com células $\mathrm{NCl} 60$ apontam uma interessante aplicação como fotoprotetores. ${ }^{84}$

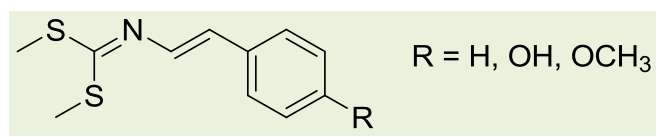

Figura 12. Análogos de tridentatóis fotoprotetores ${ }^{84}$

Compton e colaboradores promoveram a esterificação entre os óleos de rícino e de lesquerella com ácido cinâmico e ácido $p$ metóxi-cinâmico (Figura 13). Estes óleos são ricos em triglicerídeos hidroxilados e a esterificação a $200^{\circ} \mathrm{C}$, em atmosfera inerte, forneceu o óleo cinâmico (A) e o óleo $p$ metóxi-cinâmico (B) que absorveram em 260$315 \mathrm{~nm}\left(\lambda_{\max } 270 \mathrm{~nm}\right)$ e $250-345 \mathrm{~nm}\left(\lambda_{\max } 305\right.$ $\mathrm{nm})$, respectivamente. ${ }^{85}$

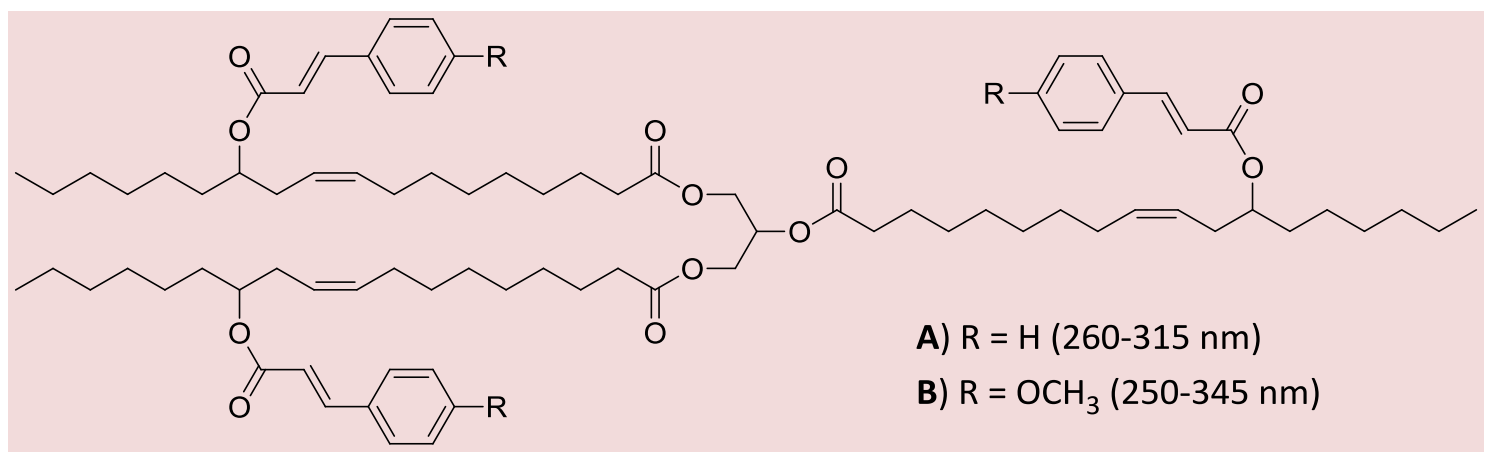

Figura 13. Estrutura do óleo que contém o grupo cinâmico e $p$-metóxi-cinâmico sintetizados por Compton e colaboradores ${ }^{85}$

Derivados do éster glicérico de $p$ metóxicinamato foram obtidos em bons rendimentos e apresentaram boa estabilidade frente à hidrólise dérmica. A reação inicial do 1,3-di-hidróxipronan-2-ona com os cloretos de ácidos graxos apropriados e, posteriormente com o ácido $p$ metoxicinâmico, forneceu os respectivos produtos conforme apresentado na Figura 14. Os compostos absorveram próximos de
$310 \mathrm{~nm}$ e o ensaio de hidrólise enzimática com o derivado octanoílico (A) apresentou um resultado semelhante ao fotoprotetor comercial OMC, enquanto o palmitoílico (B) se mostrou promissoramente superior. Além disto, (B) também apresentou um maior tempo de adesão na pele, frente ao OMC, o que sugere uma maior eficiência do produto sintetizado em detrimento ao filtro solar comercial. ${ }^{80}$ 


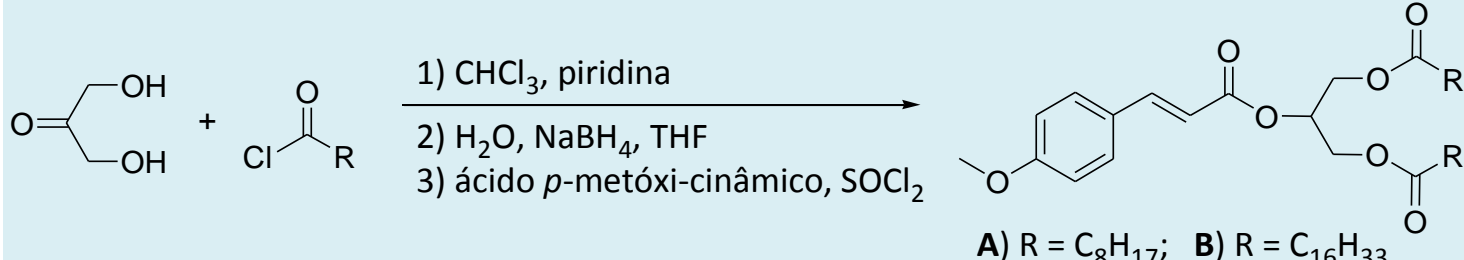

Figura 14. Síntese geral dos derivados do éster glicérico com $p$-metóxicinamato ${ }^{80}$

O FPS, in vitro e in vivo, também foi avaliado nas substâncias (A e B, Figura 14) e no fotoprotetor comercial OMC. Os ensaios foram realizados adicionando-se diferentes concentrações destes ativos em uma formulação cosmética padrão de fase oleosa em fase aquosa $(\mathrm{O} / \mathrm{W})$. Os testes apresentaram resultados promissores, onde numa dosagem de $7,5 \%$ o composto (B) forneceu um FPS de 15,4 in vitro e 16,0 in vivo, enquanto o OMC apresentou FPS de 15,3 e 15,8 , respectivamente. $^{86}$ Foram realizados testes de fototoxicidade destas substâncias e os resultados dos ensaios biológicos e microbiológicos não apresentaram reações de indução fototóxicas. $^{87}$

Asiri e Ismail sintetizaram derivados de naftopiranos através do emprego de um novo método de preparação. $O$ composto precursor foi obtido pela reação entre 2hidróxi-1-naftaldeído com trifenilfosfina e posterior emprego do acetilenodicarboxilato de dietila. Derivações subsequentes levaram a formação dos produtos finais (Figura 15). As substâncias sintetizadas ( $\mathbf{A}-\mathbf{C})$ são potenciais agentes fotoprotetores UVA-UVB tendo em vista o largo espectro de absorção UV evidenciado $(300-400 \mathrm{~nm}){ }^{88}$<smiles>CCOC(=O)C1=Cc2c(ccc3ccccc23)O[C@H]1C(=O)OCC</smiles><smiles>[B]c1cc2c(ccc3ccccc32)oc1=O</smiles><smiles>Cc1c(O[C@@H]2CC(=O)NNC2=O)ccc2ccccc12</smiles>

Figura 15. Naftopiranos sintetizados por Asiri e Ismail ${ }^{88}$

Aproveitando as características fotoprotetoras do PABA, Ricci e colaboradores, em 2005, reagiram cloreto cianúrico com o éster metílico do PABA obtendo a triazina correspondente (Figura
16). Este derivado apresentou absorção UVA (335 nm) e um alto peso molecular (528 $\mathrm{g} / \mathrm{mol})$, conferindo boas características para os fotoprotetores orgânicos melhorados. ${ }^{89}$ 


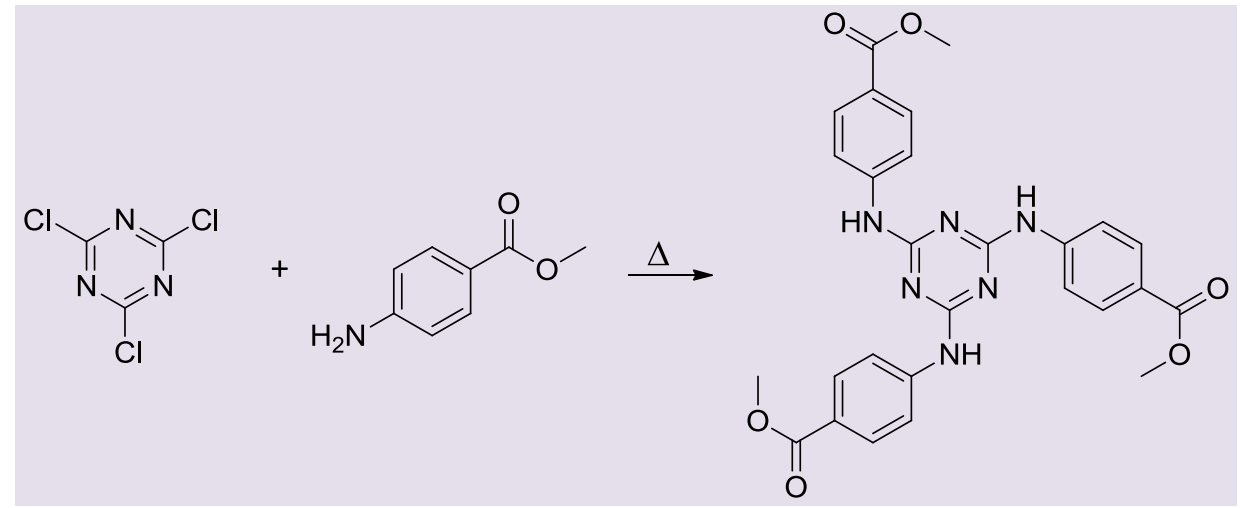

Figura 16. Síntese da triazina fotoprotetora UVA ${ }^{89}$

Compton e colaboradores promoveram a transesterificação enzimática do fotoprotetor ferulato de etila (4-hidróxi-3-metóxicinamato de etila) com óleo de semente de soja para a obtenção de fotoprotetores orgânicos lipofílicos (Figura 17). Os monoacilgliceróis (A) e os diacilgliceróis (B) ferulados obtidos tiveram sua fotoproteção investigada e se mostraram ótimos absorvedores UVA. ${ }^{90}$<smiles>[R]OCC(CO[R])OC(=O)/C=C/c1ccc(O)c(OC)c1</smiles>

Figura 17. Monoacilgliceróis (A) e diacilgliceróis (B) ferulados ${ }^{90}$

Diversos derivados do dibenzoilmetano foram sintetizados e investigados quanto ao seu potencial fotoprotetor (Figura 18). Os protótipos foram obtidos pela reação de condensação $^{81}$ entre a acetofenona e benzoatos de fenila substituídos. Estas reações fornecem $\beta$-dicetonas que tautomerizam para a forma enólica de maior estabilidade em função da ligação de hidrogênio intramolecular. As substâncias sintetizadas absorveram por volta de 340 a $360 \mathrm{~nm}$, indicando uma possível aplicação como filtros UVA. Além disso, alguns derivados metoxilados (A-D) apresentaram ótimos resultados nos ensaios de fotoestabilidade e fototoxicidade corroborando, portanto, seu potencial emprego como agentes de fotoproteção. ${ }^{91}$

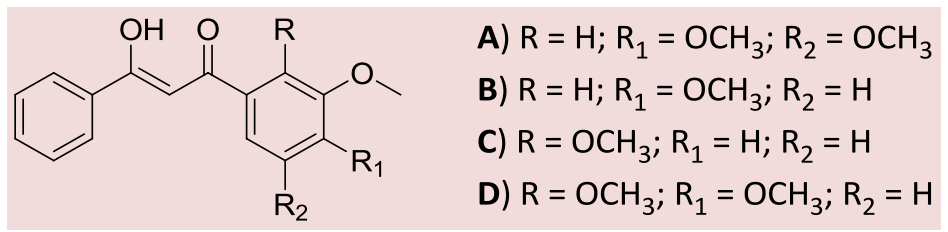

Figura 18. Derivados do dibenzoilmetano sintetizados por Hubaud e colaboradores ${ }^{91}$

Venditti e colaboradores sintetizaram uma nova substância a qual foi classificada como sendo um absorvedor UV multi-ativo (Figura 19). O derivado cinamato sintetizado apresentou importantes características básicas, como a proteção UVB, a fotoestabilidade e a não toxicidade, bem como uma interessante propriedade 
antioxidante comparada a vitamina $\mathrm{E}$ e ao 2,6-di-t-butil-4-metilfenol, antioxidantes clássicos. A ação antioxidante é promovida pelo grupamento nitróxido presente na sua estrutura. Desta forma, esta substância pode ser indicada tanto no emprego da fotoproteção quanto para o combate contra os radicais livres responsáveis pelo envelhecimento celular. ${ }^{92}$

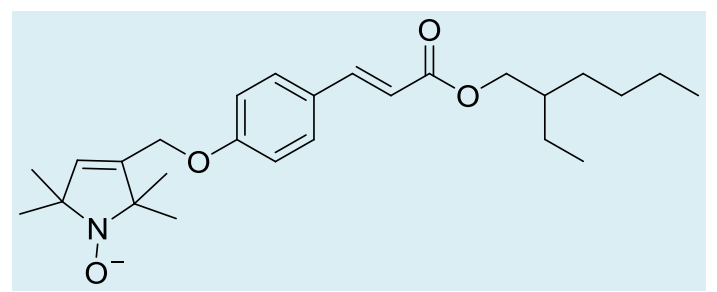

Figura 19. Absorvedor cinâmico UV multi-ativo sintetizado por Venditti e colaboradores ${ }^{92}$

Recentemente, em 2011, metaciclofenos fenólicos foram derivatizados com grupamentos cinâmicos e avaliados quanto ao seu FPS (Figura 21). Um derivado em especial (C), apresentou absorção UV em amplo espectro (280-350 nm), com $\lambda_{\max } 312$ nm (UVB) e um significante coeficiente de absorção molar $\left(\varepsilon>5 \times 10^{4}\right)$. Contudo, os ensaios de FPS em formulações cosméticas a $2 \%$ mostraram um menor FPS deste protótipo $(5,2)$ em detrimento ao $\mathrm{OMC}(6,4)$ nas mesmas condições. ${ }^{95}$

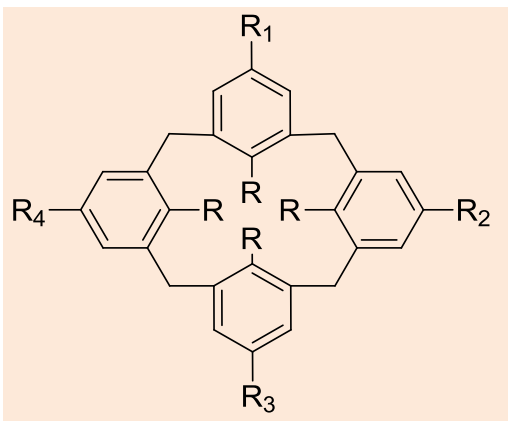

Figura 21. Derivados cinâmicos de metaciclofenos ${ }^{95}$
A) $\mathrm{R}=\mathrm{OC}_{3} \mathrm{H}_{7} ; \mathrm{R}_{1}, \mathrm{R}_{2}$ e $\mathrm{R}_{3}=\mathrm{H} ; \mathrm{R}_{4}$ = grupo cinâmico

B) $\mathrm{R}=\mathrm{OH} ; \mathrm{R}_{1}$ e $\mathrm{R}_{3}=\mathrm{H} ; \mathrm{R}_{2}$ e $\mathrm{R}_{4}=$ grupo cinâmico

C) $\mathrm{R}=\mathrm{OC}_{3} \mathrm{H}_{7} ; \mathrm{R}_{1}=\mathrm{H} ; \mathrm{R}_{2}, \mathrm{R}_{3}$ e $\mathrm{R}_{4}=$ grupo cinâmico
O ácido salicílico é um fotoprotetor UVB citotóxico, ultrapassado e com o seu uso proibido por todas as agências reguladoras em função da sua alta permeabilidade cutânea. ${ }^{11}$ Ainda assim, Yan e colaboradores, em 2011, avaliaram as propriedades fotoprotetoras de amidas lipofílicas análogas ao ácido salicílico (Figura 22). O derivado dodecílico da salicilamida (C) apresentou um interessante log $P(5,37)$, evitando a permeação cutânea e apresentando boa adesão a pele. No entanto, o ensaio de hidrólise enzimática evidenciou sua considerável fotodegradação a ácido salicílico. ${ }^{60}$ 


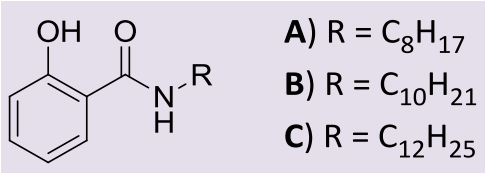

Figura 22. Salicilamidas lipofílicas ${ }^{60}$

Em uma nova estratégia sintética, Fischer e colaboradores, em 2011, empregaram a luteolina (filtro UVA) como precursora na obtenção de derivados fotoprotetores UVB e UVC. ${ }^{96}$ Esta substância natural foi submetida a reações de substituição nucleofílica em carbonos arílicos e acílicos ${ }^{81}$ para a geração de novos protótipos orgânicos de proteção solar. Os compostos sintetizados (A-D) (Figura 23) possuem alto peso molecular e apresentam boa fotoestabilidade. ${ }^{96}$<smiles>O=c1cc(-c2ccc(OCCO)c(OCCO)c2)oc2cc(OCCO)cc(OCCO)c12</smiles><smiles>[R]C(=O)Oc1cc(OC([R])=O)c2c(=O)cc(-c3ccc(OC([R])=O)c(OC([R])=O)c3)oc2c1</smiles>

B) $\mathrm{R}=\mathrm{C}_{10} \mathrm{H}_{21}$

C) $\mathrm{R}=\mathrm{C}_{12} \mathrm{H}_{25}$

D) $\mathrm{R}=\mathrm{C}_{14} \mathrm{H}_{29}$

Figura 23. Compostos derivados da luteolina ${ }^{96}$

A síntese orgânica é empregada tanto para a obtenção de novas moléculas quanto em reações que buscam a otimização dos filtros já comercializados. Villa e colaboradores sintetizaram derivados comerciais cinâmicos, salicílicos e parabênicos empregando reações via microondas (MO). ${ }^{97}$ Sob a ótica da química verde, também via MO, o filtro comercial homosalato foi obtido rapidamente e em bons rendimentos. ${ }^{98} \mathrm{Em}$ uma alternativa à síntese de Witting e de Horner-WadswothEmmons $^{81}$ com ilídios para a obtenção de ésteres $\quad(E)$ - $\alpha, \beta$-insaturados, List $\mathrm{e}$ colaboradores reportaram a síntese dos filtros comerciais metóxicinamato de octila e de isoamila partindo do $p$ metóxibenzaldeído. $^{99}$ Em 2012, Sharma e Degani sintetizaram o OMC em bom rendimento, via reações de Heck e empregando o líquido iônico tetrafluoroborato de $\mathrm{N}$-butilmorfolínio como solvente. ${ }^{100}$
2.2.3. Fotoprotetores orgânicos em nanocompostos

Morabito e colaboradores, em 2011, revisaram os nanocompostos aplicados à fotoproteção, bem como suas vantagens e perspectivas. ${ }^{7}$ Assim como no caso da síntese de novos protótipos que não permeiem o extrato córneo em função das suas propriedades estratégicas, a síntese de moléculas que servirão de suporte para estes ativos poderiam contribuir no processo de fotoproteção. ${ }^{7,101-103}$ Para tanto, a nanotecnologia, compreendida como a pesquisa a nível atômico, molecular ou macromolecular da ordem de 1 a $100 \mathrm{~nm}$, se mostra uma ferramenta atual e promissora. Muito embora na área farmacêutica e cosmética essas dimensões ultrapassem excessivamente os $100 \mathrm{~nm}, \quad$ a nanobiotecnologia na produção de nanocosméticos dermatológicos apresenta significativas vantagens, dentre as quais estão a proteção dos ativos quanto à degradação física, química ou biológica e o prolongamento de tempo de resistência do 
agente ativo na camada córnea., ${ }^{704}$ Nos filtros solares, além destes benefícios, estes veículos evitam a permeação cutânea das moléculas fotoprotetoras por estarem envolvidas por sua nanoestrutura. ${ }^{7,102,103,105}$

Diversos estudos são realizados nesta vertente, ${ }^{101-103,105-107}$ como por exemplo, Jiménez e colaboradores verificaram a baixa permeação cutânea do OMC quando nanoencapsulado. Os resultados mostraram que $\mathrm{O} O M C$ encapsulado em poli $(\varepsilon$ caprolactonas) reduz em cerca de três vezes a acumulação epidérmica. ${ }^{105} \mathrm{O}$ filtro orgânico BZF-3 foi incorporado em monoesferas de sílica numa concentração aproximada de 0,2 mmol por grama de material. Os nanocompostos apresentaram diâmetros de 100,250 e $500 \mathrm{~nm}$ e foram funcionalizados com o fotoprotetor tanto interna quanto externamente. $\mathrm{O}$ fotoprotetor incorporado ao nanocomposto apresentou fotoestabilidade. ${ }^{101}$

OMC, BZF-3 e avobenzona foram empregados em conjunto no preparo de diferentes nanopartículas lipídicas. 0 nanocomposto proveniente da cera de carnaúba apresentou absorção em amplo espectro (UVA-UVB) e excelente incorporação dos filtros, tendo em vista que a natureza da matriz lipídica influencia na absorção. ${ }^{102}$

Mota e colaboradores, em 2008, investigaram a liberação de $\mathrm{OMC}$ incluso em lipossoma e em $\beta$-ciclodextrina. A formulação contendo OMC incorporado em lipossoma promoveu a retenção deste fotoprotetor por um maior tempo, justificado, portanto, pela lipofilia do OMC aos componentes oleosos do lipossoma. Ainda sim, o OMC incluso na $\beta$ ciclodextrina apresentou menor liberação quando comparado à formulação do $\mathrm{OMC}$ não encapsulado. ${ }^{103}$ Todavia, as $\beta$ ciclodextrinas são oligossacarídeos cíclicos que, em função de sua conformação, possuem uma cavidade central lipofílica e uma superfície externa hidrofílica. ${ }^{108}$ Assim, sua purificação final é de suma importância, pois a existência de moléculas não inclusas afetarão os resultados dos ensaios de fotoproteção. Acompanhamentos via ressonânica magnética nuclear de hidrogênio (RMN ${ }^{1} \mathrm{H}$ ) mostraram que o emprego de solução aquosa de metanol a $50 \%$ é eficiente na purificação final. ${ }^{109}$ Esta temática possui uma investigação recente, 2011 e 2012, pelo desenvolvimento de muitos e diversificados estudos. ${ }^{110-113}$

Diversos trabalhos voltados para a síntese de novos compostos orgânicos fotoprotetores foram continuados em pesquisas nanomoleculares. Os monoacilgliceróis e diacilgliceróis ferulados (Figura 17) obtidos por Compton e colaboradores foram dispersos a $50 \%$ em solução aquosa fornecendo microemulsões estáveis. Estes nanocompostos encapsulados apresentaram boa absorbância UV e estabilidade superior aos óleos ferulados puros. ${ }^{90} \mathrm{O}$ derivado da BZF preparado por Poon e colaboradores (Figura 11) foi incorporado a filmes poliméricos de poli(metacrilato de metila) (PMMA) e avaliado quanto à fotoproteção. ${ }^{83}$ Esta mesma sistemática foi seguida por Murtinho e colaboradores onde seus compostos (Figura 20) também foram revestidos com PMMA. ${ }^{93}$ A encapsulação polimérica é um método promissor para carrear moléculas fotoprotetoras, haja vista a grande variedade e versatilidade da química de polímeros. $^{7}$ Estes nanocompostos são frequentemente avaliados quanto a seus princípios de fotoproteção. ${ }^{102,103}$

\subsection{Protocolo de fotoproteção}

O controle de qualidade (CQ) dos fotoprotetores orgânicos comerciais é estabelecido dentro das normas básicas de boas práticas de fabricação (BPF). Para as substâncias puras, são realizados desde testes organolépticos (aspecto, cor e odor) a análises físico-químicas tais como, pontos de fusão ou ebulição, pH, solubilidade, índice de refração e gravidade específica. A cromatografia em fase gasosa (CG) e a CLAE são amplamente empregadas no $C Q$, 
principalmente na determinação da pureza, enquanto os métodos espectroscópicos (UV, IV e RMN) são utilizados na caracterização das moléculas. ${ }^{11}$ Contudo, os produtos acabados não possuem uma metodologia oficial para dosagem dos agentes ativos de proteção solar, exceto para o derivado glicerílico do PABA, muito embora o seu uso seja proibido desde 1992. As principais técnicas analíticas empregadas na quantificação das substâncias fotoprotetoras nos filtros UV são a CLAE e a CG. ${ }^{114,115}$
Fotoprotetores comerciais podem ser avaliados quando em separados ou em associações de filtros solares e também quando em soluções ou em formulações cosméticas. As loções cosmésticas empregadas como veículos para avaliação de FPS devem apresentar boa emulsificação, consistência, estabillidade, espalhabilidade e, inevitavelmente, a não absorção de radiação UV. A Tabela 11 apresenta duas formulações diferentes com $8 \%$ de homosalato (UVB). ${ }^{39,46}$

Tabela 11. Composições de loções para fotoprotetores UVB (homosalato a 8 \%)

\begin{tabular}{cccc}
\hline $\begin{array}{c}\text { FDA } \\
\text { Composição* }\end{array}$ & $\begin{array}{c}\text { Santos e colaboradores } \\
\text { \% por peso }\end{array}$ & $\begin{array}{c}\text { Composição* } \\
\text { \% por peso }\end{array}$ \\
Homosalato & 8,00 & Homosalato & 8,00 \\
Ácido esteárico & 4,00 & Ácido esteárico & 2,70 \\
Lanolina & 5,00 & Estearato de glicerila & 2,00 \\
Vaselina & 2,50 & Óleo Mineral & 2,00 \\
Propilparabeno & 0,05 & Miristato de isopropila & 1,40 \\
Metilparabeno & 0,10 & Éter cetílico/estearílico & 2,00 \\
EDTA dissódico** & 0,05 & Propilparabeno & 0,10 \\
Propileno glicol & 5,00 & Metilparabeno & 0,10 \\
Trietanolamina & 1,00 & Glicerina & 3,00 \\
Água purificada & 74,30 & Trietanolamina & 0,20 \\
& & Água purificada & 78,50 \\
\hline
\end{tabular}

*Substâncias de grau cosmético, alimentício ou farmacêutico; ** Sal dissódico do ácido etilenodiaminotetracético

O estudo de novas moléculas sintéticas requer uma bateria de ensaios que apresentem informações amplas e seguras a respeito dos compostos candidatos a fotoprotetores orgânicos. A sequência de execução dos testes deve seguir uma ordem lógica e sensata (Tabela 12), de maneira que, por exemplo, antes de se verificar os ensaios fotobiológicos de um protótipo, sua pureza, seu FPS in vitro, sua fotoestabilidade e a possibilidade de hidrólise já devem ter sido investigadas e, sobretudo, terem apresentado bons resultados. ${ }^{5,59}$ 
Tabela 12. Protocolo de fotoproteção para novas substâncias

\begin{tabular}{cc}
\hline Ordem & Ensaios \\
$1 ㅇ$ & Pureza \\
$2 ㅇ$ & FPS/FP-UVA in vitro \\
$3 ㅇ$ & Fotoestabilidade \\
$4 ㅇ$ & Hidrólise \\
5 & Ensaios fotobiológicos \\
$6 ㅇ$ & Sinergia em formulações \\
70 & Permeabilidade cutânea \\
8 & Imunossupressão \\
9 & Resistência à água \\
$10^{\circ} \circ$ & FPS/FP-UVA in vivo \\
\hline
\end{tabular}

A constatação da ausência de impurezas na amostra, principalmente as absorvedoras de UV, é de grande importância haja vista a sensibilidade do método espectroscópico de UV realizado constantemente nas etapas seguintes. As técnicas cromatográficas (CLAE e CG) e os métodos espectroscópicos (UV, IV e RMN) são empregados na determinação da pureza. ${ }^{11}$

O procedimento utilizado para avaliação do FPS in vitro de loções cosméticas, ${ }^{44}$ quando utilizado em substâncias puras, deve considerar a concentração molar do fotoprotetor. Este fato está associado a eventual diferença de massa entre os compostos. Em 2011, Nascimento e colaboradores, em testes inicias, verificaram um maior FPS do protótipo sintetizado (FPS 8,3) frente ao OMC (FPS 7,5), ambos numa concentração molar de $2 \times 10^{-5} \mathrm{M}$. A fotoestabilidade deve ser verificada em simuladores solares com potência e emissão de radiação conhecidos. Por exemplo, sob uma potência de $900 \mathrm{~W}$ e uma lâmpada com emissão de $3 \mathrm{~J} \cdot \mathrm{m}^{2} \cdot \mathrm{s}^{-1}$ de UVB, após irradiação por 4 horas $\left(40 \mathrm{KJ} / \mathrm{m}^{2}\right)$, o protótipo sintetizado mostrou um irrelevante decaimento de FPS (6,3 para 6,2), enquanto o OMC se mostrou menos fotoestável, regredindo de um FPS 5,1 para 4,1. ${ }^{116}$
Nos filtros solares, formulações cosméticas, as moléculas fotoprotetoras são empregadas em emulsão de óleo em água (O/W) que possuem pelo menos $70 \%$ de água. Estas moléculas entram em contato com o extrato córneo que promove sua hidrólise enzimática, além de serem utilizados, na prática, sob a ação dos raios UV do sol. Isto evidencia, portanto, a necessidade dos testes de resistência à hidrólise. Freitas e colaboradores avaliaram os seus novos fotoprotetores orgânicos sintetizados via lipase induzida, in vitro, frente ao fungo comercial Rhizomucor miehei. Os resultados mostraram que 0 protótipo palmitólico foi quase três vezes mais estável a hidrólise enzimática, quando comparado ao $\mathrm{OMC}^{80}$

As implicações dérmicas estão compreendidas entre os estudos fotobiológicos de fototoxicidade e fotomutagenicidade, além da permeabilidade cutânea e da imunossupressão. A fototoxicidade foi investigada por Mariani e colaboradores através dos ensaios de fotohemólise e fotoperoxidação lipídica. Estas fotoinduções são indicativas de degradação da membrana celular pelas reações com EROs produzidas pelos fotoprotetores. Os resultados dos seus estudos em radiação UVA não indicaram 
fototoxicidade relevante para os derivados sintetizados. $^{82} \quad \mathrm{O}$ teste de fotomutagenicidade foi investigado por Santos e colaboradores em cepas de Escherichia coli pelo método de colorimetria bacteriológica para genotoxinas. Após a incubação inicial na presença dos compostos fotoprotetores, a atividade da $\beta$ galactosidase foi avaliada e as substâncias não apresentaram propriedades mutagênicas. ${ }^{117}$

A sinergia em formulações cosméticas se trata da eventual diminuição, ou aumento, da ação fotoprotetora de uma substância em função das possíveis interações ou reações químicas desta com os diversos compontes químicos de uma formulação cosmética. Este ensaio pode ser avaliado pelo emprego de técnicas cromatográficas e espectroscópicas, com posteriores verificações fotobiológicas. ${ }^{10,11,12}$

A permeabilidade cutânea também foi verificada por Mariani e colaboradores empregando amostras de pele de humanos adultos (30 a 40 anos) provenientes de sirurgias de redução de seios. Utilizando CLAE para detectar a passagem das amostras pelo extrato córneo e sua presença nas membranas epidérmicas, pôde ser concluido que os protótipos lipofílicos sintetizados não apresentaram permeabilidade dérmica, podendo ser indicados em produtos dermatológicos. ${ }^{82}$

A imunossupressão pode ser investigada pela fotoizomerização do ácido urocânico. A capacidade fotoprotetora dos agentes antissolares é medida pela inibição da formação do isômero cis deste ácido nos linfócitos epidérmicos, pois a passagem da radiação solar promoveria a fotoisomerização do isômero trans, mais estável. ${ }^{118}$ Esta forma isomérica pode ser determinada sob uma exposição à radiação UVB de $100 \mathrm{~mJ} / \mathrm{cm}^{2}$ (in vivo) e $200 \mathrm{~mJ} / \mathrm{cm}^{2}$ (ex vivo). ${ }^{119}$

Por último, a resistência do produto à água e o FPS/FP-UVA in vivo, conforme já discutido, devem ser determinados dentro dos padrões estabelecidos pela ANVISA, FDA e COLIPA. A resistência à água é avaliada pela verificação do fator de fotoproteção antes e após a imersão em água numa temperatura de $29{ }^{\circ} \mathrm{C}$ e em períodos de 20 minutos, intercalados com tempos de secagem. Estes critérios de qualidade asseguram a eficácia dos protetores solares garantindo um nível seguro de proteção contra os nocivos raios UV. ${ }^{2,13,14,36,38,39}$

\section{Considerações Finais}

Demograficamente, o Brasil está localizado em uma região que recebe grande intensidade de radiação solar. Cada vez mais aumenta o número de pessoas que exercem atividades profissionais em ambientes externos ficando, portanto, diariamente sob os riscos dos raios do sol. Somado a isso, o hábito contemporâneo da "cultura ao corpo" faz com que muitas pessoas fiquem excessivamente expostas aos raios solares, principalmente em toda a imensa extensão litorânea. Como se não bastasse, a redução da camada de ozônio por agentes químicos permite a entrada de uma maior quantidade de radiação UV. Os recentes avanços em pesquisas mostram que a radiação UVA é tão nociva quanto à radiação mais forte UVB, sendo o tempo para a ocorrência de um problema de saúde o diferencial entre ambas. Assim, mesmo em dias nublados ou até mesmo em certos ambientes fechados há incidência de radiação UVA e, a exposição contínua a esses raios podem levar a problemas de saúde que poderiam ser evitados. Poucas doenças possuem o privilégio da prevenção, como no caso do câncer de pele. $O$ custeio para o tratamento desta doença é extremamente superior aos investimentos em sua prevenção. Estudos também comprovam que o uso frequente e correto de filtros solares com um FPS seguro impede a ocorrência do câncer de pele. Considerando o exposto, envidencia-se uma promissora e importante linha de pesquisa, preconizada nas necessidades decorrentes de novos fotoprotetores orgânicos ideais e, sobretudo, com o subsídio empresarial, 
contemporâneo e pragmático, para tornar esses produtos acessíveis à população.

\section{Agradecimentos}

Os autores agradecem às agências de fomento CNPq, CAPES e FAPERJ pelo apoio financeiro, ao Instituto Militar de Engenharia e a Universidade Federal do Rio de Janeiro pela infraestrutura e a Organização Mundial da Saúde pela autorização de uso das fotografias do câncer de pele na Figura 1.

\section{Referências Bibliográficas}

${ }^{1}$ Panorama do Setor 2011. Disponível em: $<$ http://www.abihpec.org.br/2012/04/panor ama-do-setor-2011/>. Acesso em: 13 julho 2012.

${ }^{2}$ Resolução RDC $n^{0} 30$, de 01 de junho de $2012 . \quad$ Disponível em: $<$ http://bvsms.saude.gov.br/bvs/saudelegis/a nvisa/2012/rdc0030 $0106 \quad 2012$.pdf>.

Acesso em: 20 julho 2012.

${ }^{3}$ Murphy, G. M.; Hawk, J. L. M. Sunscreens. Journal of the Royal Society of Medicine 1986, 79, 254. [PubMed]

${ }^{4}$ Costa, M. L.; Silva, R. R. Ataque à pele. Química Nova na Escola 1995, 1, 3. [Link]

${ }^{5}$ Gasparro, F. P.; Mitchnick, M.; Nash, J. F. A Review of Sunscreen Safety and Efficacy. Photochemistry and Photobiology 1998, 68, 243. [CrossRef] [PubMed]

${ }^{6}$ Flor, J.; Davolos, M. R.; Correa, M. A. Protetores solares. Química Nova 2007, 30, 153. [CrossRef]

${ }^{7}$ Morabito, K.; Shapley, N. C.; Steeley, K. G.; Tripathi, A. Review of sunscreen and the emergence of non-conventional absorbers and their applications in ultraviolet protection. International Journal of Cosmetic Science 2011, 33, 385. [CrossRef] [PubMed]
${ }^{8}$ Cabral, L. D. S.; Pereira, S. O.; Partata, A. K. Filtros solares e fotoprotetoresmais utilizados nas formulações do Brasil. Revista Científica do ITPAC, Araguaína 2011, 4, 1. [Link]

${ }^{9}$ Mulliken, J. S.; Russak, J. E.; Rigel, D. S. The Effect of Sunscreen on Melanoma Risk. Dermatologic Clinics 2012, 30, 369. [CrossRef] [PubMed]

${ }^{10}$ Utumi, M. G.; Campi, P. M. Em Cosmiatria em dermatologia: usos e aplicações; Borelli, S., ed.; Roca: São Paulo, 2007.

${ }^{11}$ Shaath, N. A.; The encyclopedia of ultraviolet filters, APC: New York, 2007.

${ }^{12}$ Glaser, D. A.; Prodanovic, E. Em Cosmecêuticos; Draelos, Z. D., ed.; 2a. ed., Elsevier: Rio de Janeiro, 2009.

${ }^{13}$ Guidelines: method for in vitro determination of UVA protection, 2011. Disponível em: $<$ https://www.cosmeticseurope.eu/publicati ons-cosmetics-europe-

association/guidelines.html?view=item\&id=3 3>. Acesso em: 26 julho 2012.

${ }^{14}$ Labeling and effectiveness testing; sunscreen drug products for over-thecounter human use; delay of compliance dates. Disponível em: <http://www.gpo.gov/fdsys/pkg/FR-2012-0511/pdf/2012-11390.pdf>. Acesso em: 07 agosto 2012.

${ }^{15}$ Lucas, R.; McMichael, T.; Smith, W.; Armstrong. B.; Solar ultraviolet radiation: global burden of disease from solar ultraviolet radiation, Environmental Burden of Disease Series, n. 13., World Health Organization: Geneva, 2006. [Link]

${ }^{16}$ Pavia, D. L.; Lampman, G. M.; Kriz, G. S.; Vyvyan, J. R.; Introdução à espectroscopia, Cengage Learning: São Paulo, 2010.

${ }^{17}$ Harris, D. C.; Análise química quantitativa, 6a. ed., LTC: Rio de Janeiro, 2005.

${ }^{18}$ Guaratini, T.; Collejon, D. R.; Pires, D. C.; Lopes, J. N. C.; Lima, L. M.; Neto, D. G.; Sustovick, C.; Lopes, N. P. Fotoprotetores derivados de produtos naturais: perspectivas de mercado e interações entre o setor 
produtivo e centros de pesquisa. Química Nova 2009, 32, 717. [CrossRef]

${ }^{19}$ Lund, L. P.; Timmins, G. S. Melanoma, long wavelength ultraviolet and sunscreens: Controversies and potential resolutions. Pharmacology \& Therapeutics 2007, 114, 198. [CrossRef] [PubMed]

${ }^{20}$ Stary, A.; Robert, C.; Sarasin, A. Deleterious effects of ultraviolet $A$ radiation in human cells. Mutation Research/DNA Repair 1997, 383, 1. [CrossRef]

${ }^{21}$ Fourtanier, A.; Moyal, D.; Seite, S. UVA filters in sun-protection products: regulatory and biological aspects. Photochemical \& Photobiological Sciences 2012, 11, 81. [CrossRef] [PubMed]

${ }^{22}$ Ivry, G. B.; Ogle, C. A.; Shim, E. K. Role of Sun Exposure in Melanoma. Dermatologic Surgery 2006, 32, 481. [CrossRef] [PubMed]

${ }^{23}$ Wlaschek, M.; Tantcheva-Poór, I.; Naderi, L.; Ma, W.; Schneider, L. A.; Razi-Wolf, Z.; Schüller, J.; Scharffetter-Kochanek, K. Solar UV irradiation and dermal photoaging. Journal of Photochemistry and Photobiology B: Biology 2001, 63, 41. [CrossRef]

${ }^{24}$ Afaq, F.; Adhami, V. M.; Mukhtar, H. Photochemoprevention of ultraviolet B signaling and hotocarcinogenesis. Mutation Research/Fundamental and Molecular Mechanisms of Mutagenesis 2005, 571, 153. [CrossRef] [PubMed]

${ }^{25}$ Volkovova, K.; Bilanicova, D.; Bartonova, A.; Letašiová, S.; Dusinska, M. Associations between environmental factors and incidence of cutaneous melanoma. Review. Environmental Health 2012, 11, 1. [CrossRef] [PubMed]

${ }^{26}$ Lees, M.; Skin care: beyond the basics, 3a. ed., Thomson Dermar Learning: New York, 2007.

${ }^{27}$ Barreiros, A. L. B. S.; David, J. M.; David, J. P. Estresse oxidativo: relação entre geração de espécies reativas e defesa do organismo. Química Nova 2006, 29, 113. [CrossRef]

${ }^{28}$ Said, T.; Dutot, M.; Martin, C.; Beaudeux, J.-L.; Boucher, C.; Enee, E.; Baudouin, C.; Warnet, J.-M.; Rat, P. Cytoprotective effect against UV-induced DNA damage and oxidative stress: Role of new biological UV filter. European Journal of Pharmaceutical Sciences 2007, 30, 203. [CrossRef] [PubMed]
${ }^{29}$ Ultraviolet radiation and the intersun programme. Disponível em: $<$ http://www.who.int/uv/health/en/index.ht $\mathrm{ml}$. Acesso em: 17 julho 2012.

${ }^{30}$ Tipos de câncer: pele melanoma. Disponível em: $<$ http://www2.inca.gov.br/wps/wcm/connect /tiposdecancer/site/home/pele melanoma>. Acesso em: 17 julho 2012.

${ }^{31}$ Tipos de câncer: pele não melanoma. Disponível em: $<$ http://www2.inca.gov.br/wps/wcm/connect tiposdecancer/site/home/pele nao melano ma>. Acesso em: 17 julho 2012.

${ }^{32}$ Francis, S. O.; Mahlberg, M. J.; Johnson, K. R.; Ming, M. E.; Dellavalle, R. P. Melanoma chemoprevention. Journal of the American Academy of Dermatology 2006, 55, 849. [CrossRef] [PubMed]

${ }^{33}$ Campanha nacional de prevenção ao câncer de pele. Disponível em: $<$ http://www.sbd.org.br/campanha/cancer/d efault.aspx>. Acesso em: 17 julho 2012.

${ }^{34}$ Moyal, D. D.; Fourtanier, A. M. Broadspectrum sunscreens provide better protection from solar ultraviolet-simulated radiation and natural sunlight-induced immunosuppression in human beings. Journal of the American Academy of Dermatology 2008, 58, 149. [CrossRef] [PubMed]

${ }^{35}$ Purim, K. S. M.; Leite, M. Fotoproteção e exercício físico. Revista Brasileira de Medicina do Esporte 2010, 16, 224. [CrossRef]

${ }^{36}$ Resolução RDC $n^{\circ} 47$, de 16 de março de $2006 . \quad$ Disponível em: <http://www.anvisa.gov.br/cosmeticos/legis/ especifica registro.htm>. Acesso em: 23 julho 2012.

${ }^{37}$ Velasco, M. V. R.; Balogh, T. S.; Pedriali, C. A.; Sarruf, F. D.; Pinto, C. A. S. O.; Kaneko, T. M.; Baby, A. R. Novas metodologias analíticas para avaliação da eficácia fotoprotetora (in vitro) - revisão. Revista de Ciências Farmacêuticas Básica e Aplicada 2011, 32, 27. [Link]

${ }^{38}$ Guidelines for evaluating sun product water resistance, 2005. Disponível em: $<$ https://www.cosmeticseurope.eu/publicati ons-cosmetics-europe- 
association/guidelines.html?view=item\&id=1 8>. Acesso em: 26 julho 2012.

${ }^{39}$ Sunscreen drug products for over-thecounter human: final monograph. Disponível em:

$<$ http://www.fda.gov/downloads/Drugs/Dev elopmentApprovalProcess/DevelopmentReso urces/Over-the-

CounterOTCDrugs/StatusofOTCRulemakings/ ucm090244.pdf>. Acesso em: 26 julho 2012.

${ }^{40}$ Springsteen, A.; Yurek, R.; Frazier, M.; Carr, K. F. In vitro measurement of sun protection factor of sunscreens by diffuse transmittance. Analytica Chimica Acta 1999, 380, 155. [CrossRef]

${ }^{41}$ Bendová, H.; Akrman, J.; Krejčí, A.; Kubač, L.; Jírová, D.; Kejlová, K.; Kolářová, H.; Bradec, M.; Malý, M. In vitro approaches to evaluation of Sun Protection Factor. Toxicology in Vitro 2007, 21, 1268. [CrossRef] [PubMed]

${ }^{42}$ Garoli, D.; Pelizzo, M. G.; Bernardini, B.; Nicolosi, P.; Alaibac, M. Sunscreen tests: Correspondence between in vitro data and values reported by the manufacturers. Journal of Dermatological Science 2008, 52, 193. [CrossRef] [PubMed]

${ }^{43}$ Garoli, D.; Pelizzo, M. G.; Nicolosi, P.; Peserico, A.; Tonin, E.; Alaibac, M. Effectiveness of different substrate materials for in vitro sunscreen tests. Journal of Dermatological Science 2009, 56, 89. [CrossRef] [PubMed]

${ }^{44}$ Mansur, J. S.; Breder, M. N. R.; Mansur, M. C. d'A.; Azulay, R. D. Determinação do fator de proteção solar por espectrofotometria. Anais Brasileiros de Dermatologia 1986, 61, 121.

${ }^{45}$ Sayre, R. M.; Agin, P. P.; LeVEE, G. J.; Marlowe, E. A comparison of in vivo and in vitro testing of sunscreening formulas. Photochemistry and Photobiology 1979, 29, 559. [CrossRef] [PubMed]

${ }^{46}$ Santos, E. P.; Freitas, Z. M.; Souza, K. R.; Garcia, S. In Vitro and In Vivo Determinations of Sun Protection Factors of Sunscreen Lotions with Octylmethoxycinnamate. International Journal of Cosmetic Science 1999, 21, 1. [CrossRef] [PubMed]
${ }^{47}$ Diffey, B. L.; Tanner, P. R.; Matts, P. J.; Nash, J. F. In vitro assessment of the broadspectrum ultraviolet protection of sunscreen products. Journal of the American Academy of Dermatology 2000, 43, 1024. [CrossRef] [PubMed]

${ }^{48}$ Baby, A. R.; Balogh, T. S.; Pedriali, C. A.; Kanedo, T. M.; Velascos, M. V. R. UVA Iprotection effectiveness of bioactive compound and organic UV filters: an in vitro assessment. Química Nova 2009, 32, 1321. [CrossRef]

${ }^{49}$ Hojerová, J.; Medovcíková, A.; Mikula, M. Photoprotective efficacy and photostability of fifteen sunscreen products having the same label SPF subjected to natural sunlight. International Journal of Pharmaceutics 2011, 408, 27. [CrossRef] [PubMed]

${ }^{50}$ Mahmoud, B. H.; Ruvolo, E.; Hexsel, C. L.; Liu, Y.; Owen, M. R.; Kollias, N.; Lim, H. W.; Hamzavi, I. H. Impact of Long-Wavelength UVA and Visible Light on Melanocompetent Skin. Journal of Investigative Dermatology 2012, 130, 2092. [CrossRef] [PubMed]

${ }^{51}$ Schalka, S.; Addor, F. A. S.; Agelune, C. M.; Pereira, V. M. C. Sunscreen protection against visible light: a new proposal for evaluation. Surgical \& Cosmetic Dermatology 2012, 3, 45. [Link]

${ }^{52}$ Balzani, V.; Scandola, F. Chemistry and Light. Part 1: Photochemistry, a New Dimension of Chemistry. Química Nova 1996, 19, 542. [Link]

${ }^{53}$ Bonda, C. A. Em Sunscreens: Regulation and Commercial Development; Shaath, N. A, ed.; 3a. ed., Taylor and Francis: Boca Raton, 2005.

${ }^{54}$ Schudel, P.; $\quad$ Schwarzenbach, R.; Gonzenbach, H. U.; Givaudan Corporation 07/001,279 1987. (US4713473) [Link]

${ }^{55}$ Santos, A. J. M.; Miranda, M. S.; Silva, J. C. G. E. The degradation products of UV filters in aqueous and chlorinated aqueous solutions. Water Research 2012, 46, 3167. [CrossRef] [PubMed]

${ }^{56}$ Pattanaargson, S.; Munhapol, T.; Hirunsupachot, P.; Luangthongaram, P. Photoisomerization of octyl methoxycinnamate. Journal of 
Photochemistry and Photobiology A: Chemistry 2004, 161, 269. [CrossRef]

${ }^{57}$ Huong, S. P.; Andrieu, V.; Reynier, J.-P.; Rocher, E.; Fourneron, J.-D. The photoisomerization of the sunscreen ethylhexyl p-methoxy cinnamate and its influence on the sun protection factor. Journal of Photochemistry and Photobiology A: Chemistry 2007, 186, 65. [CrossRef]

${ }^{58}$ MacManus-Spencer, L. A.; Tse, M. L.; Klein, J. L.; Kracunas, A. E. Aqueous Photolysis of the Organic Ultraviolet Filter Chemical Octyl Methoxycinnamate. Environmental Science \& Technology 2011, 45, 3931. [CrossRef] [PubMed]

${ }^{59}$ Nohynek, G. J.; Schaefer, H. Benefit and Risk of Organic Ultraviolet Filters. Regulatory Toxicology and Pharmacology 2001, 33, 285. [CrossRef] [PubMed]

${ }^{60}$ Yan, Y.-D.; Sung, J. H.; Lee, D. W.; Kim, J. S.; Jeon, E.-M.; Kim, D.-D.; Kim, D. W.; Kim, J. O.; Piao, M. G.; Li, D. X.; Yong, C. S.; Choi, H. G. Evaluation of physicochemical properties, skin permeation and accumulation profiles of salicylic acid amide prodrugs as sunscreen agent. International Journal of Pharmaceutics 2011, 419, 154. [CrossRef] [PubMed]

${ }^{61}$ Marvel, C. S.; Sperry, W. M. Em Organic Syntheses; Gilman, H.; Blatt, A. H., eds.; coll. vol. I, 2a. ed., John Wiley and Sons: New York, 1941.

${ }^{62}$ Gaspar, L. R.; Campos, P. M. B. G. M. Evaluation of the photostability of different UV filter combinations in a sunscreen. International Journal of Pharmaceutics 2006, 307, 123. [CrossRef] [PubMed]

${ }^{63}$ Couteau, C.; Faure, A.; Fortin, J.; Paparis, E.; Coiffard, L. J. M. Study of the photostability of 18 sunscreens in creams by measuring the SPF in vitro. Journal of Pharmaceutical and Biomedical Analysis 2007, 44, 270. [CrossRef] [PubMed]

${ }^{64}$ Hayden, C. G. J.; Cross, S. E.; Anderson, C.; Saunders, N. A.; Roberts, M. S. Sunscreen Penetration of Human Skin and Related Keratinocyte Toxicity after Topical Application. Skin Pharmacology and Physiology 2005, 18, 170. [CrossRef] [PubMed]

${ }^{65}$ Hayden, C. G. J.; Roberts, M. S.; Benson, H. A. E. Systemic absorption of sunscreen after topical application. The Lancet 1997, 350, 863. [CrossRef]

${ }^{66}$ Vilela, F. M. P.; Fonseca, Y. M.; Vicentini, F. T. M. C.; Fonseca, M. J. V.; Amaral, M. P. H. Determination of three ultraviolet filters in sunscreen formulations and from skin penetration studies by high-performance liquid chromatography. Química Nova 2011, 34, 879. [CrossRef]

${ }^{67}$ Wosicka, H.; Cal, K. Targeting to the hair follicles: Current status and potential. Journal of Dermatological Science 2010, 57, 83. [CrossRef] [PubMed]

${ }^{68}$ Morpurgo, G.; Babudri, N.; Fioretti, B.; Franciolini, F.; Catacuzzeno, L. Synthetic aromatic compounds interfering with melanogenesis are responsible of the rising trend of malignant melanoma incidence. Medicinal Hypotheses 2011, 76, 374. [CrossRef] [PubMed]

${ }^{69}$ Wang, S. Q.; Osterwalder, U.; Jung, K. Ex vivo evaluation of radical sun protection factor in popular sunscreens with antioxidants. Journal of the American Academy of Dermatology 2011, 65, 525. [CrossRef] [PubMed]

${ }^{70}$ Ferrari, M.; Oliveira, M. S. C.; Nakano, A. K.; Rocha-Filho, P. A. Determinação do fator de proteção solar (FPS) in vitro e in vivo de emulsões com óleo de andiroba (Carapa guianensis). Revista Brasileira de Farmacognosia 2007, 17, 626. [CrossRef]

${ }^{71}$ Violante, I. M. P.; Souza, I. M.; Venturini, C. L.; Ramalho, A. F. S.; Santos, R. A. N.; Ferrari, M. Avaliação in vitro da atividade fotoprotetora de extratos vegetais do cerrado de Mato Grosso. Revista Brasileira de Farmacognosia 2009, 19, 452. [CrossRef]

72 Hupel, M.; Poupart, N.; Gall, E. A. Development of a new in vitro method to evaluate the photoprotective sunscreen activity of plant extracts against high UV-B radiation. Talanta 2011, 86, 362. [CrossRef] [PubMed]

${ }^{73}$ Polonini, H. C.; Raposo, N. R. B.; Brandão, M. A. F. Fotoprotetores naturais no contexto da saúde pública brasileira. Revista de APS 2011, 14, 216. [Link]

${ }^{74} \mathrm{Hu}, \mathrm{G}$.; Wang, X. Research on a natural sunscreen from Chinese herbs. International 
Journal of Cosmetic Science 1998, 20, 175. [CrossRef] [PubMed]

${ }^{75}$ Sinha, R. P.; Klisch, M.; Gröniger, A.; Häder, D.-P. Ultraviolet-absorbing/screening substances in cyanobacteria, phytoplankton and macroalgae. Journal of Photochemistry and Photobiology B: Biology 1998, 47, 83. [CrossRef]

${ }^{76}$ Sharma, P.; Lygo, B.; Lewis, W.; Moses, J. E. Biomimetic Synthesis and Structural Reassignment of the Tridachiahydropyrones. Journal of the American Chemical Society 2009, 131, 5966. [CrossRef] [PubMed]

77 Yagura, T.; Makita, K.; Yamamoto, H.; Menck, C. F. M.; Schuch, A. P. Biological Sensors for Solar Ultraviolet Radiation. Sensors 2011, 11, 4277. [CrossRef] [PubMed] 78 Gao, Q.; Garcia-Pichel, F. Microbial ultraviolet sunscreens. Nature Reviews Microbiology 2011, 9, 791. [CrossRef] [PubMed]

${ }^{79}$ Menegatti, R.; Fraga, C. A. M.; Barreiro, E. J. A Importância da Síntese de Fármacos. Química Nova na Escola 2001, 3, 16. [Link]

${ }^{80}$ Freitas, Z. M. F.; Santos, E. P.; Rocha, J. F.; Dellamora-Ortiz, G. M.; Gonçalves, J. C. S. A new sunscreen of the cinnamate class: Synthesis and enzymatic hydrolysis evaluation of glyceryl esters of $p$ methoxycinnamic acid. European Journal of Pharmaceutical Sciences 2005, 25, 67. [CrossRef] [PubMed]

${ }^{81}$ Smith, M. B.; March, J.; March's advanced organic chemistry: reactions, mechanisms and structure, 6a. ed., John Wiley and Sons: New Jersey, 2007.

82 Mariani, E.; Neuhoff, C.; Bargagna, A.; Bonina, F.; Giacchi, M.; De Guidi, G.; Velardita, A. Synthesis, in vitro percutaneous absorption and phototoxicity of new benzylidene derivatives of 1,3,3-trimethyl-2oxabicyclo[2.2.2]octan-6-one as potential UV sunscreens. International Journal of Pharmaceutics 1998, 161, 65. [CrossRef]

83 Poon, T.; Mclntyre, J. P. The Preparation of a UV-Light-Absorbing Polymer: A ProjectOriented Laboratory Experiment for the Introductory Organic Chemistry Curriculum. Journal of Chemical Education 1999, 76, 1523. [CrossRef]
84 Jayatilake, G. S.; Baker, B. J. Synthetic Studies of the Tridentatols. Organic Letters 1999, 1, 661. [CrossRef]

${ }^{85}$ Compton, D. L.; Laszlo, J. A.; Isbell, T. A. Cinnamoyl esters of lesquerella and castor oil: Novel sunscreen active ingredients. Journal of the American Oil Chemists' Society 2004, 81, 945. [CrossRef]

${ }^{86}$ Freitas, Z. M. F.; Gonçalves, J. C. S.; Santos, E. P.; Vergnanini, A. Glyceridic esters of $p$ methoxycinnamic acid. A new sunscreen of the cinnamate class. International Journal of Cosmetic Science 2001, 23, 147. [CrossRef] [PubMed]

${ }^{87}$ Freitas, Z. M. F.; Machado, P. A.; Dellamora-Ortiz, G. M.; Santos, E. P.; Gonçalves, J. C. S. Evaluation of phototoxicity of the sunscreens: 1,2,3-propanetriol 1,3dipalmitoyl-2-p-methoxycinnamoyl and 1,2,3propanetriol 1,3-dioctanoyl-2-pmethoxycinnamoyl. STP Pharma Sciences 2000, 10, 239. [Link]

${ }^{88}$ Asiri, A. M.; Ismail, I. M. I. Synthesis of diethyl 2H-naphtho[2,1,b]pyran-2,3dicarboxylate and some related compounds as UV absorbers. Pigment \& Resin Technology 2005, 34, 33. [CrossRef]

${ }^{89}$ Ricci, A.; Chrétien, M. N.; Sayari, A.; Scaiano, J. C. Photophysical Properties of Methyl Triazone Included in MCM-41. Photochemistry and Photobiology 2005, 81, 949. [CrossRef] [PubMed]

${ }^{90}$ Compton, D. L.; Kenar, J. A.; Laszlo, J. A.; Felker, F. C. Starch-encapsulated, soy-based, ultraviolet-absorbing composites with feruloylated monoacyl- and diacylglycerol lipids. Industrial Crops and Products 2007, 25, 17. [CrossRef]

${ }^{91}$ Hubaud, J.-C.; Bombarda, I.; Decome, L.; Wallet, J.-C.; Gaydou, E. M. Synthesis and spectroscopic examination of various substituted 1,3-dibenzoylmethane, active agents for UVA/UVB photoprotection. Journal of Photochemistry and Photobiology B: Biology 2008, 92, 103. [CrossRef] [PubMed] 92 Venditti, E.; Spadoni, T.; Tiano, L.; Astolfi, P.; Greci, L.; Littarru, G. P.; Damiani, E. In vitro photostability and photoprotection studies of a novel 'multi-active' UV-absorber. Free 
Radical Biology and Medicine 2008, 45, 345. [CrossRef] [PubMed]

${ }^{93}$ Murtinho, D. M. B.; Serra, M. E. S.; Pineiro, M. Síntese de fotoprotetores e sua imobilização em poli(metacrilato de metilo): um projeto integrado de química orgânica, química de polímeros e fotoquímica. Química Nova 2010, 33, 1805. [CrossRef]

${ }^{94}$ Conard, C. R.; Dolliver, M. A. Em Organic Syntheses, coll. vol. I, 2a. ed.; Gilman, H.; Blatt, A. H.; John Wiley and Sons: New York, 1941.

${ }^{95}$ Chawla, H. M.; Pant, N.; Kumar, S.; Mrig, S.; Srivastava, B.; Kumar, N.; Black, S. StC. Synthesis and evaluation of novel tetrapropoxycalix[4]arene enones and cinnamates for protection from ultraviolet radiation. Journal of Photochemistry and Photobiology B: Biology 2011, 105, 25. [CrossRef] [PubMed]

${ }^{96}$ Fischer, F.; Zufferey, E.; Bourgeois, J.-M.; Héritier, J.; Micaux, F. UV-ABC screens of luteolin derivatives compared to edelweiss extract. Journal of Photochemistry and Photobiology B: Biology 2011, 103, 8. [CrossRef] [PubMed]

${ }^{97}$ Villa, C.; Baldassari, S.; Gambaro, R.; Mariani, E.; Loupy, A. Eco-friendly methodologies for the synthesis of some aromatic esters, well-known cosmetic ingredients. International Journal of Cosmetic Science 2005, 27, 11. [CrossRef] [PubMed]

${ }^{98}$ Gambaro, R.; Villa, C.; Baldassari, S.; Mariani, E.; Padori, A.; Bassi, A. M. 3,3,5Trimethylcyclohexanols and derived esters: green synthetic procedures, odour evaluation and in vitro skin cytotoxicity assays. International Journal of Cosmetic Science 2006, 28, 439. [CrossRef] [PubMed]

${ }^{99}$ List, B.; Doehring, A.; Fonseca, M. T. H.; Job, A.; Torres, R. R. A Practical, efficient, and atom economic alternative to the Wittig and Horner-Wadsworth-Emmons reactions for the synthesis of (E)- $\alpha, \beta$-unsaturated esters from aldehydes. Tetrahedron. 2006, 62, 476. [CrossRef]

${ }^{100}$ Sharma, Y. O.; Degani, M. S. The Heck reaction of aryl bromides: a green protocol for synthesis of 2-ethylhexyl-4-methoxy cinnamate. Green Chemistry Letters and Reviews 2010, 3, 201. [CrossRef]
${ }^{101}$ Walenzyk, T.; Carola, C.; Buchholz, H.; König, B. Synthesis of mono-dispersed spherical silica particles containing covalently bonded chromophores. International Journal of Cosmetic Science 2005, 27, 177. [CrossRef] [PubMed]

${ }^{102}$ Xia, Q.; Saupe, A.; Müller, H.; Souto, E. B. Nanostructured lipid carriers as novel carrier for sunscreen formulations. International Journal of Cosmetic Science 2007, 29, 473. [CrossRef] [PubMed]

${ }^{103}$ Mota, A. C. V.; Volpato, N. M.; Freitas, Z. M. F.; Santos, E. P. Estudo de liberação in vitro do filtro solar $p$-metoxicinamato de octila incluso em lipossoma e $\beta$ ciclodextrina. Revista de Ciências Farmacêuticas Básica e Aplicada 2008, 29, 285. [Link]

${ }^{104}$ Fronza, T.; Guterres, S.; Pohlmann, A.; Teixeira, H.; Nanocosméticos, Gráfica UFRGS: Porto Alegre, 2007.

105 Jiménez, M. M.; Pelletier, J.; Bobin, M. F.; Martini, M. C. Influence of encapsulation on the in vitro percutaneous absorption of octyl methoxycinnamate. International Journal of Pharmaceutics 2004, 272, 45. [CrossRef] [PubMed]

${ }^{106}$ Anselmi, C.; Centini, M.; Rossi, C.; Ricci, M.; Rastrelli, A.; Andreassi, M.; Buonocore, A.; Rosa, C. L. New microencapsulated sunscreens: technology and comparative evaluation. International Journal of Pharmaceutics 2002, 242, 207. [CrossRef]

${ }^{107}$ Karpkird, T.; Wanichweacharungruang, S. Synthesis and photostability of methoxycinnamic acid modified cyclodextrins. Journal of Photochemistry and Photobiology A: Chemistry 2010, 212, 56. [CrossRef]

${ }^{108}$ Cal, K.; Centkowska, K. Commentary to the article "Human skin penetration of the major components of Australian tea tree oil applied in its pure form and as a $20 \%$ solution in vitro". European Journal of Pharmaceutics and Biopharmaceutics 2008, 68, 467. [CrossRef] [PubMed]

${ }^{109}$ Mota, A. C. V.; Freitas, Z. M. F.; Todeschini, A. R.; Cabral, L. M.; Santos, E. P. Inclusão do Filtro Solar p-Metoxicinamato de Octila em $\beta$-Ciclodextrina e Avaliação da Purificação dos Complexos de Inclusão por 
RMN ${ }^{1} \mathrm{H}$. Latin American Journal of Pharmacy 2009, 28, 97. [Link]

${ }^{110}$ Machado, J. K. F. B.; Marçal, A. L.; Lima, O. J.; Ciuffi, K. J.; Nassar, E. J.; Calefi, P. S. Materiais híbridos orgânico-inorgânicos (ormosil) obtidos por sol-gel com potencial uso como filtro solar. Química Nova 2011, 34, 945. [CrossRef]

${ }^{111}$ Berbicz, F.; Nogueira, A. C.; Neto, A. M.; Natali, M. R. M.; Baesso, M. L.; Matioli, G. Use of photoacoustic spectroscopy in the characterization of inclusion complexes of benzophenone-3-hydroxypropyl- $\beta$ -

cyclodextrin and ex vivo evaluation of the percutaneous penetration of sunscreen. European Journal of Pharmaceutics and Biopharmaceutics 2011, 79, 449. [CrossRef] [PubMed]

${ }^{112}$ Lacatusu, I.; Badea, N.; Murariu, A.; Meghea, A. The encapsulation effect of UV molecular absorbers into biocompatible lipid nanoparticles. Nanoscale Research Letters 2011, 6, 1. [CrossRef] [PubMed]

${ }^{113}$ Shi, L.; Shan, J.; Ju, Y.; Aikens, P.; Prud'homme, R. K. Nanoparticles as delivery vehicles for sunscreen agents. Colloids and Surfaces A: Physicochemical and Engineering Aspects 2012, 396, 122. [CrossRef]

${ }^{114}$ Salvador, A.; Chisvert, A. An environmentally friendly ("green") reversed-phase liquid chromatography method for UV filters determination in cosmetics. Analytica Chimica Acta 2005, 537, 1. [CrossRef]

${ }^{115}$ Peck, A. M. Analytical methods for the determination of persistent ingredients of personal care products in environmental matrices. Analytical and Bioanalytical Chemistry 2006, 386, 907. [CrossRef] [PubMed]

${ }^{116}$ Nascimento, L. F.; Aguiar, A. P.; Freitas, Z. M. F.; Santos, E. P.; Resumo da 34a Reunião Anual da Sociedade Brasileira de Química, Florianópolis, Brasil, 2011. [Link]

117 Santos, E. P.; Garcia, S.; Freitas, Z. M. F.; Barth, A. L. Avaliação fotobiológica de uma mistura de filtros solares. Visão Acadêmica 2001, 2, 71. [Link]

${ }^{118}$ Finlay-Jones, J. J.; Hart, P. H. Photoprotection: sunscreens and the immunomodulatory effects of UV irradiation. Mutation Research/Fundamental and Molecular Mechanisms of Mutagenesis 1998, 422, 155. [CrossRef]

${ }^{119}$ Molen, R. G.; Out-Luiting, C.; Driller, H.; Claas, F. H. J.; Koerten, H. K.; Mommaas, A. M. Broad-Spectrum Sunscreens Offer Protection Against Urocanic Acid Photoisomerization by Artificial Ultraviolet Radiation in Human Skin. Journal of Investigative Dermatology 2000, 115, 421. [CrossRef] [PubMed] 